\title{
Early Growth Response-1 Induces and Enhances Vascular Endothelial Growth Factor-A Expression in Lung Cancer Cells
}

\author{
Hiroaki Shimoyamada, ${ }^{*}$ Takuya Yazawa, ${ }^{*}$ \\ Hanako Sato, ${ }^{* \dagger}$ Koji Okudela, ${ }^{*}$ Jun Ishii, ${ }^{*}$ \\ Masashi Sakaeda, ${ }^{*}$ Korehito Kashiwagi, ${ }^{*}$ \\ Takehisa Suzuki, ${ }^{*}$ Hideaki Mitsui, ${ }^{*}$ \\ Tetsukan Woo, ${ }^{\ddagger}$ Michihiko Tajiri, ${ }^{\S}$ \\ Takahiro Ohmori, ${ }^{\S}$ Takashi Ogura, ${ }^{\pi}$ \\ Munetaka Masuda, ${ }^{\ddagger}$ Hisashi Oshiro," \\ and Hitoshi Kitamura* \\ From the Departments of Pathology, ${ }^{*}$ and Surgery, ${ }^{\ddagger}$ Yokohama \\ City University Graduate School of Medicine, and the Division of \\ Diagnostic Pathology," Yokohama City University Hospital, \\ Yokohama, Kanagawa; the Department of Anatomy, ${ }^{\dagger}$ St . \\ Marianna University School of Medicine, Sugao, Miyamae-ku, \\ Kawasaki, Kanagawa; and the Divisions of Thoracic Surgery, ${ }^{S}$ \\ and Respiratory Medicine, "Tanagawa Prefectural \\ Cardiovascular and Respiratory Center Hospital, Tomioka- \\ bigashi, Kanazawa-ku, Yokohama, Kanagawa, Japan
}

Vascular endothelial growth factor-A (VEGF-A) is crucial for angiogenesis, vascular permeability, and metastasis during tumor development. We demonstrate here that early growth response-1 (EGR-1), which is induced by the extracellular signal-regulated kinase (ERK) pathway activation, activates $V E G F-A$ in lung cancer cells. Increased EGR-1 expression was found in adenocarcinoma cells carrying mutant $K$-RAS or EGFR genes. Hypoxic culture, siRNA experiment, luciferase assays, chromatin immunoprecipitation, electrophoretic mobility shift assays, and quantitative RT-PCR using EGR-1-inducible lung cancer cells demonstrated that EGR-1 binds to the proximal region of the $V E G F-A$ promoter, activates $V E G F-A$ expression, and enhances hypoxia inducible factor $1 \alpha$ (HIF-1 $\alpha$ )mediated VEGF-A expression. The EGR-1 modulator, NAB-2, was rapidly induced by increased levels of EGR-1. Pathology samples of human lung adenocarcinomas revealed correlations between EGR-1/HIF-1 $\alpha$ and VEGF-A expressions and relative elevation of EGR-1 and VEGF-A expression in mutant $K$-RAS- or EGFR-carrying adenocarcinomas. Both EGR-1 and VEGF-A expression increased as tumors dedifferenti- ated, whereas HIF-1 $\alpha$ expression did not. Although weak correlation was found between EGR-1 and NAB-2 expressions on the whole, NAB-2 expression decreased as tumors dedifferentiated, and inhibition of DNA methyltransferase/histone deacetylase increased NAB-2 expression in lung cancer cells despite no epigenetic alteration in the $N A B-2$ promoter. These findings suggest that EGR-1 plays important roles on $V E G F-A$ expression in lung cancer cells, and epigenetic silencing of transactivator(s) associated with $N A B-2$ expression might also contribute to upregulate VEGF-A expression. (Am J Pathol 2010, 177:70-83; DOI: 10.2353/ajpath.2010.091164)

Vascular endothelial growth factor (VEGF)-A, -B, -C, -D, and $-E$ play important roles in tumor progression. VEGF-A (also called vascular permeability factor) is a heparinbinding dimeric cytokine that stimulates proliferation and migration of endothelial cells by binding to VEGF receptor-1 (VEGFR-1, also called Flt-1) and VEGFR-2 (also called KDR/FIk-1). ${ }^{1-4}$ VEGF-A produced by cancer cells impacts tumor progression by accelerating angioneogenesis and cavity effusions. ${ }^{1,3,4}$ VEGF-A expression is significantly correlated with neovascularization in resected lung cancer tissues and is an important prognostic factor ${ }^{5-9}$; in animal models, the level of VEGF-A expression in lung cancers directly correlates with the extent of pleural effusion. ${ }^{10,11}$ Recently, significant effort has been made at developing therapeutic strategies that target biological functions of VEGF-A and VEGFRs. ${ }^{1,2}$

VEGF-A expression is controlled by multiple genetic and environmental signals. Hypoxia inducible factor 1

Supported by the Grant-in-Aid for Scientific Research from the Ministry of Education, Culture, Sports, Science, and Technology of Japan (Nos. 19590358 and 60381513), and by a grant from the Smoking Research Foundation of Japan.

Accepted for publication March 22, 2010.

Address reprint requests to Takuya Yazawa, M.D., Ph.D., Department of Pathology, Yokohama City University Graduate School of Medicine, 3-9 Fukuura, Kanazawa-ku, Yokohama, Kanagawa 236-0004, Japan. E-mail: tkyazawa@med.yokohama-cu.ac.jp. 
(HIF-1) is a primary regulator of VEGF-A under hypoxic conditions. HIF-1 is a heterodimeric basic helix-loop-helix transcription factor composed of HIF- $1 \alpha$ and HIF- $1 \beta$; HIF- $1 \alpha$ is the key regulatory component for VEGF-A induction. ${ }^{12}$ Under oxygen-rich conditions, conserved prolyl residues within the oxygen-dependent degradation domain of HIF- $1 \alpha$ are promptly hydroxylated by prolyl hydroxylases. ${ }^{13}$ As a result, HIF- $1 \alpha$ binds von HippelLindau (VHL) tumor suppressor protein and is targeted for degradation via the ubiquitin-proteasome pathway. ${ }^{13}$ However, under hypoxic conditions, prolyl hydroxylase is inactive, resulting in stabilization of HIF- $1 \alpha$. The stabilization of HIF- $1 \alpha$ is enhanced by inactivation of the asparaginyl hydroxylase enzyme $\mathrm{FIH}-1$, resulting in association of $\mathrm{HIF}-1 \alpha$ with $\mathrm{p} 300 / \mathrm{CBP}$ coactivator proteins. ${ }^{14}$

Impairment of the $\mathrm{VHL}$ gene in cancer cells is tightly associated with stabilization of HIF- $1 \alpha$, resulting in VEGF-A overexpression. Germline mutation of $\mathrm{VHL}$ causes a hereditary tumor syndrome with an associated risk for development of central nervous system and retinal hemangioblastomas, renal clear cell carcinomas, and pheochromocytomas. ${ }^{15}$ In addition to frequent loss of heterozygosity, mutation and silencing of the $\mathrm{VHL}$ gene due to promoter hypermethylation occurs in approximately 50\% and $10 \%$ of sporadic noninherited renal clear cell carcinomas, respectively. ${ }^{16}$ However, mutational inactivation and epigenetic silencing of $V H L$ is not a common event in the molecular carcinogenesis of lung cancers, whereas loss of heterozygosity at 3p25-26, where VHL is located, is relatively frequent. ${ }^{17-19}$ These observations strongly suggest that HIF- $1 \alpha$-independent pathways are also important for VEGF-A expression in lung cancer cells.

It has recently been demonstrated that oncogenic RAS mutation stimulates VEGF-A expression. ${ }^{20-22}$ We previously reported that a transgene of the oncogenic mutant $K$-RAS upregulates early growth response-1 (EGR-1) through the ERK signal pathway in airway epithelial cells. ${ }^{23}$ EGR-1, also called NGFI-A, is a transcription factor that is rapidly induced by a large number of growth factors, cytokines, and injurious stimuli and activates genes through the consensus GC-rich binding motif $5^{\prime}$-GCG(T/G)GGGCG-3' ${ }^{24}$ EGR-1 activity is regulated by the corepressors NGFI-A binding protein 1 and 2 (NAB-1 and -2). ${ }^{25-27} \mathrm{NAB}-1$ is constitutively expressed in most cells, ${ }^{28}$ whereas NAB-2 is induced by EGR-1. ${ }^{29}$

Lung adenocarcinomas often carry oncogenic mutant $K-R A S$ or EGFR, ${ }^{30,31}$ and the occurrence of K-RAS and EGFR mutations are strictly mutually exclusive. ${ }^{32}$ Both activating $K-R A S$ and EGFR activate the ERK pathway. It has been reported that EGFR mutation upregulates EGR-1 expression and that EGFR tyrosine kinase inhibitor induces antiangiogenic effects via VEGF-A repression. ${ }^{33,34}$

Because the promoter region of VEGF-A (GenBank accession no. AF095785) possesses GC-rich sequences and several putative EGR-1-binding sites, we hypothesized that EGR-1 directly regulates VEGF-A expression in lung cancer cells. We demonstrate here that EGR-1 binds to the proximal region of the VEGF-A promoter, induces HIF-1 $\alpha$-independent VEGF-A expression, and enhances HIF- $1 \alpha$-mediated VEGF-A expression.

\section{Materials and Methods}

\section{Cells and Cell Culture}

Seven human nonsmall-cell lung cancer lines (TKB6, TKB14, A549, H358, PC9, HCC827, and TKB5) and a human embryonic kidney cell line (HEK293T) were used in this study. ${ }^{35,36}$ TKB6, TKB14, and TKB5 cell lines were kindly provided by Kamma H (Kyorin University School of Medicine, Tokyo, Japan), PC9 was purchased from ImmunoBiological Laboratories Co. (Gunma, Japan), and A549, H358, HCC827, and HEK293T cell lines were purchased from American Type Culture Collection (ATCC, Manassas, VA). A549 and H358 cells carry mutant K-RAS gene, and PC9 and HCC827 cells carry mutant EGFR gene. Cells were cultured in Dulbecco's modified Eagle's medium (TKB6, TKB14, A549, H358, PC9, TKB5, and HEK293T) or RPMI1640 medium (HCC827) supplemented with 10\% heat-inactivated fetal calf serum, $100 \mathrm{U} / \mathrm{ml}$ penicillin, and $100 \mu \mathrm{g} / \mathrm{ml}$ streptomycin and were maintained at $37^{\circ} \mathrm{C}$ under $5 \% \mathrm{CO}_{2}$. EGR-1 expression in transfected cells (TKB5pRevEGR-1 and TKB5pRevEmpty; see below) was induced by adding $1 \mu \mathrm{g} / \mathrm{ml}$ (final concentration) doxycycline (Clontech, Mountain View, CA) to the culture medium. Hypoxic condition $\left(0.5 \% \mathrm{O}_{2}, 5 \% \mathrm{CO}_{2}\right)$ was made by Anaeropack System (Mitsubishi Gas Chemical Co., Tokyo, Japan). ${ }^{37} 1.0 \times 10^{5}$ TKB5pRevEGR-1 cells were seeded in 60-mm dishes and cultivated for 48 hours in the normoxic condition. Then, dishes were placed in Anaeropack Jars following the manufacturer's instructions and were exposed to hypoxia for 8 hours. To induce EGR-1, doxycycline was added 24 hours before harvesting TKB5pRevEGR-1 cells.

\section{Western Blot Analysis}

Cultivated lung cancer cells were gently washed with PBS, harvested, lysed in extraction buffer $(20 \mathrm{mmol} / \mathrm{L}$ HEPES, pH 7.6, 20 mmol/L NaCl, 0.5 mmol/L EDTA, 10\% glycerol), and sonicated. Whole-cell lysates (50 $\mu \mathrm{g}$ total protein per sample) were separated by SDS-PAGE and transferred to nitrocellulose membranes (Schleicher \& Schuell, Keene, NH). Membranes were blocked for 1 hour at room temperature with $1 \%$ skim milk in PBS containing $0.1 \%(\mathrm{v} / \mathrm{V})$ Tween 20 (PBS-T) and then incubated for 1 hour at room temperature with diluted rabbit polyclonal anti-EGR-1 (Santa Cruz Biotechnology, Santa Cruz, CA) ${ }^{38}$ mouse monoclonal anti-HIF- $1 \alpha$ (Santa Cruz Biotechnology), ${ }^{39}$ rabbit polyclonal anti-VEGF-A (Santa Cruz Biotechnology), ${ }^{11,40}$ mouse monoclonal anti-NAB-2 (Santa Cruz Biotechnology), ${ }^{41}$ or rabbit polyclonal antiNAB-1 (AVIVA Systems Biology, San Diego, CA). ${ }^{26}$ After washing three times with PBS-T at room temperature, membranes were incubated at room temperature for 30 minutes with diluted peroxidase-labeled anti-rabbit or anti-mouse secondary antibody (Amersham Biosciences, Buckinghamshire, UK). The membranes were then washed three times for 10 minutes with PBS-T at room temperature, and immunopositive signals were visualized using an enhanced chemiluminescence detection kit (ECL; Amersham Biosciences). $\beta$-Actin was analyzed as an internal control using mouse monoclonal 
Table 1. PCR Primers Used for RT-PCR, Expression Vector Construction, Luciferase Assay, Chromatin Immunoprecipitation-Based PCR, or Bisulfite Sequencing

\begin{tabular}{|c|c|}
\hline Target & Primer sequences \\
\hline \multicolumn{2}{|l|}{ For RT-PCR } \\
\hline \multirow[t]{2}{*}{ EGR-1 } & F: 5'-GCAGCAGCAGCACCTTCAAC-3' \\
\hline & 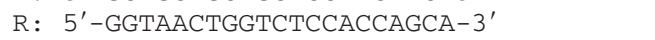 \\
\hline \multirow[t]{2}{*}{$H I F-1 a$} & F: 5'-TTTGCTGAAGACACAGAAGCAAAGA-3' \\
\hline & 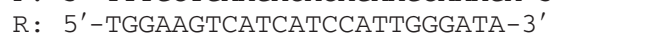 \\
\hline \multirow[t]{2}{*}{ VEGF-A } & F: 5'-GAGCCTTGCCTTGCTGCTCTAC-3' \\
\hline & 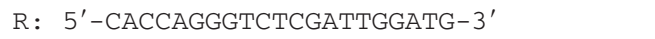 \\
\hline \multirow[t]{2}{*}{$N A B-2$} & $\mathrm{~F}:$ 5'-CATCTATGGCCGTTTCGACTCTAAG-3' \\
\hline & $\mathrm{R}: 5^{\prime}$-AGCAGCCTCGTTGATGGTGA-3' \\
\hline \multirow[t]{2}{*}{$N A B-1$} & $\mathrm{~F}:$ 5'-TGCAGGGCTTTACAGGCAGAG-3' \\
\hline & R: 5'-AGGCATTCGGAGATTCAAAGGTC-3' \\
\hline \multirow[t]{2}{*}{$\beta$-Actin } & $\mathrm{F}:$ 5'-TGGCACCCAGCACAATGAA-3' $^{\prime}$ \\
\hline & 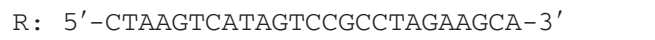 \\
\hline \multicolumn{2}{|l|}{ For EGR-1 expression vector } \\
\hline EGR-1 & $\mathrm{F}: 5^{\prime}$-GGCCCCCGCAACTGTGTCC-3' \\
\hline \multirow{2}{*}{\multicolumn{2}{|c|}{ For luciferase reporter vectors }} \\
\hline & \\
\hline \multirow[t]{2}{*}{ VEGF-A promoter $(-2362$ to +536$)$} & $\mathrm{F}: 5^{\prime}$-GAATTCTGTGCCCTCACTCCC-3' \\
\hline & $\mathrm{R}: 5^{\prime}$-CTGGGGCTGGGGGCGGTGTCT-3' \\
\hline \multirow[t]{2}{*}{ VEGF-A promoter $(-1345$ to +536$)$} & F : 5'-GGGAGGGGACTGGGGGAAGGA-3' \\
\hline & R: 5'-CTGGGGCTGGGGGCGGTGTCT-3' \\
\hline \multirow{2}{*}{ VEGF-A promoter $(-1020$ to +536$)$} & $\mathrm{F}: 5^{\prime}-\mathrm{TGCCCAGCTGCCTCCCCCTTTG-3'}$ \\
\hline & 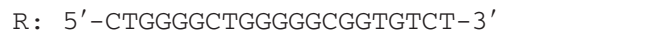 \\
\hline \multirow[t]{2}{*}{ VEGF-A promoter $(-372$ to +536$)$} & 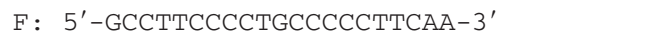 \\
\hline & 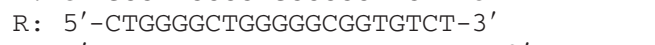 \\
\hline \multirow[t]{2}{*}{ VEGF-A promoter $(-295$ to +536$)$} & $\mathrm{F}:$ 5'-TTCCTGCTCCCTCCTCGCCAATG-3' \\
\hline & R: $5^{\prime}$-CTGGGGCTGGGGGCGGTGTCT-3' \\
\hline \multirow[t]{2}{*}{ VEGF-A promoter $(-30$ to +536$)$} & $\mathrm{F}:$ 5'-TTTTTAAAAGTCGGCTGGTAG-3' \\
\hline & 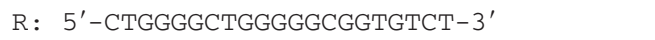 \\
\hline \multicolumn{2}{|c|}{ For chromatin immunoprecipitation-based PCR } \\
\hline \multirow[t]{2}{*}{ VEGF-A promoter } & F: 5'-ССTGстCССTCCTCGCCAATG-3' \\
\hline & $\mathrm{R}: 5^{\prime}-\mathrm{CGCTGCGCCTCCCGACA-3^{ \prime }}$ \\
\hline \multicolumn{2}{|l|}{ For bisulfite sequencing } \\
\hline \multirow[t]{2}{*}{$N A B-2$ promoter $(-756$ to -481$)$} & F: 5'-TAGATTATTTTATTGGGGTTGAGGAG-3' \\
\hline & $R: 5^{\prime}-$ CACAAATACACAAAAACACAAAAAC-3' \\
\hline \multirow[t]{2}{*}{$N A B-2$ promoter $(-479$ to +16$)$} & F: 5'-GTGGTTGTGAAATTTTTTTT-3' \\
\hline & 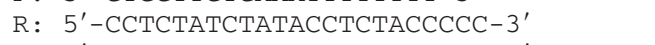 \\
\hline \multirow[t]{2}{*}{ NAB-2 promoter $(+45$ to +268$)$} & F: 5'-AGGGAGGGATAGAGTTTGGATAG-3' \\
\hline & 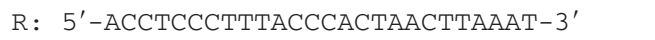 \\
\hline \multirow[t]{2}{*}{ EGR-1 promoter ( -600 to -363$)$} & F: 5'-GTTTGGGTTTTTTTAGTTTAGTTTA-3' \\
\hline & 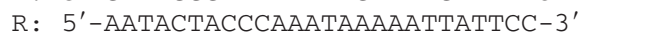 \\
\hline \multirow[t]{2}{*}{ EGR-1 promoter $(-374$ to -75$)$} & F : 5'-TTGGGTAGTATTTTATTTGGAGTGG-3' \\
\hline & R: 5'-CATATATAAAAAACAAAAAACCCTAATATA-3' \\
\hline \multirow[t]{2}{*}{ VEGF-A promoter $(-562$ to -205$)$} & F: 5'-GTTATTATAGGGAAGTTGGGTGAAT-3' \\
\hline & 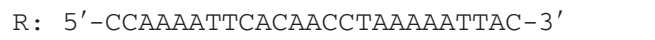 \\
\hline VEGF-A promoter $(-221$ to +237$)$ & F: 5'-TAGGTTGTGAATTTTGGTGGG-3' \\
\hline & 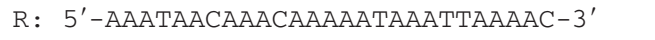 \\
\hline
\end{tabular}

$F$ and $R$ indicate forward and reverse primer sequences, respectively.

anti- $\beta$-actin (Sigma-Aldrich, St. Louis, MO). Semiquantitative analysis of protein expression levels was performed using NIH image software (National Institutes of Health, Rockville, MD).

\section{Quantitative RT-PCR}

Total RNA was extracted from cultivated lung cancer cells using TRIzol (Invitrogen, Carlsbad, CA). For quantitative RT-PCR (qRT-PCR), first-strand cDNA was synthesized from total RNA using the SuperScript FirstStrand Synthesis System (Invitrogen) according to the manufacturer's instructions. The resulting cDNA was used as a template for qRT-PCR using SYBR Premix ExTaq (Takara, Shiga, Japan) and primer sets specific for amplification of EGR-1, HIF-1 $\alpha$, VEGF-A, NAB-2, NAB-1, or $\beta$-actin (Table 1). Amplification reactions were performed using a TP800 Thermal Cycler DICE Real-Time PCR System (Takara). Data were obtained from triplicate reactions. The means and standard deviations of the copy number were normalized by the value for $\beta$-actin mRNA. Data reflect mean mRNA copy number (+SD) from triplicate reactions and were normalized to the mean $\beta$-actin mRNA copy number.

\section{RNA Interference Experiment}

Double-stranded small interfering RNAs (siRNAs) for EGR-1 (25-mer) were designated by RNAi Designer (Invitrogen) and synthesized using Stealth RNAi (Invitrogen). $2.5 \times 10^{5}$ 
of H358 cells, which carry mutant K-RAS gene, were seeded in six-well plates, and 250 pmol of siRNA duplex was transfected using X-tremeGENE siRNA transfection reagent (Roche Diagnostics, Penzberg, Germany) and OptiMEM (Invitrogen) according to the manufacture's instructions. The siRNA sequences for EGR-1 and scrambled control were 5'-AGCAAAUUUCAAUUGUCCUGGGAGA-3' and 5'-AGCGGAAUUAACUUUACUGGUCAGA-3', respectively. After the siRNA-treated $\mathrm{H} 358$ cells were cultivated for 24 hours, they were harvested and subjected to Western blot analysis.

\section{Establishment of EGR-1-Inducible Lung Cancer Cells}

To obtain EGR-1 cDNA, total RNA was extracted from cultivated A549 lung cancer cells using TRIzol and used as a template for first-strand cDNA synthesis using Superscript III (Invitrogen). EGR-1 cDNA was then synthesized using pfu polymerase (Stratagene, La Jolla, CA) and an EGR-1-specific primer set (Table 1) according to the manufacturer's instructions. The amplified cDNA, which contains the full-length EGR-1 coding region, was cloned into the pT7Blue vector (Novagen, Madison, WI) and sequenced.

We used a retrovirus-based Tet-On Advanced Inducible Gene Expression System (pTet-On Advanced and pRevTRE; Clontech) and established EGR-1-inducible clones by doxycycline treatment. First, the pTet-On Advanced vector, which expresses reverse tetracycline-controlled transactivator protein (rtTA), was transfected into TKB5 cells using Lipofectamine 2000 (Invitrogen). After neomycin $(1000 \mu \mathrm{g} / \mathrm{ml})$ selection for 3 weeks, stable transfectants were cloned. Next, EGR-1 cDNA was inserted into the pReVTRE retroviral vector, and EGR-1 cDNA-inserted pRevTRE (pRevEGR-1) and p10A1 envelop vectors were co-transfected into HEK293T cells using Lipofectamine 2000. The pRevTRE-Empty retroviral vector (pRevEmpty) was used as a control. After 24 hours of transfection, conditioned medium was collected as a viral solution. Desired genes were introduced into rtTA-transfected TKB5 cells by incubation in the presence of viral solution containing $10 \mu \mathrm{g} / \mathrm{ml}$ of polybren (Sigma-Aldrich) for 24 hours, and the desired cells (TKB5pRevEGR-1 and TKB5pRevEmpty) were obtained by hygromycin $(500 \mathrm{ng} / \mathrm{ml})$ selection for 3 weeks.

\section{VEGF-A Promoter Assay}

The VEGF-A promoter is located 2362 bp upstream from the transcription start site (GenBank accession no. AF095785). For luciferase-based promoter assays, VEGF-A promoter fragments (nucleotides $-2362,-1345,-1020$, $-372,-295$, or -30 to +536 relative to the transcription start site) were generated by PCR amplification using specific primer sets (Table 1), cloned into pT7Blue (Novagen), and then inserted into the pGL4.10 luc2 luciferase reporter vector (Promega, Madison, WI).

For VEGF-A promoter mutation analysis, a segment of the full-length VEGF-A promoter sequence was removed using Sacll and Nhel and replaced with oligonucleotides contain- ing VEGF-A promoter sequences in which one or more of the five putative EGR-1-binding regions were mutated. Because one EGR-1-binding site ( -247 to -231 ) was slightly separated from the other four, this region was named site 1. And because of the close proximity of the other four sites, the entire region ( -98 and -32 ) was named site 2 , with the individual EGR-1-binding sites therein named site 2-1, 2-2, $2-3$, and 2-4. Wild-type and mutant nucleotide sequences (sense strand) were as follows (mutated sequences are underlined): wild-type site1, 5'-GTTCCGGGGGCGGATG-3'; mutated site 1, 5'-GTTTCCTAGGGCGGATG-3'; wild-type site 2, 5'-TCCCCGCCCCCCGGGGCGGGCCGGGGGCGGGGTCCCGGCGGGGCGGAGCCATGCGCCCCCCCCTTT-3'; mutated site 2 (2-1, 2-2, 2-3, and 2-4), 5'-TCCCCGCCCTACGGGGCGGGCCTAGGGCGGGGTCCCGGCTAGGCGGAGCCATGCGCCCTACCCTTT-3'; mutated site 2-1, 2-2, and 2-3, 5'-TCCCCGCCCTACGGGGCGGGCCTAGGGCGGGGTCCCGGCTAGGCGGAGCCATGCGCCCCCCCCTTT-3'. Consequently, site 1-mutated, site 2-mutated, both site 1- and site 2 (2-1, 2-2, 2-3, and 2-4)-mutated, and site 2-1-, 2-2-, and 2-3-mutated VEGF-A promoter-inserted luciferase vectors were constructed.

Promoter-luciferase vectors were transiently transfected into TKB5pRevEGR-1 and TKB5pRevEmpty cells using FuGENE6 transfection reagent according to the manufacturer's instructions (Roche Molecular Biochemicals, Indianapolis, IN) as described previously. ${ }^{23}$ Briefly, cells were seeded at $50 \%$ confluency in six-well plates and cultivated in medium with or without $1 \mu \mathrm{g} / \mathrm{ml}$ doxycycline for 24 hours. Cells were then cotransfected with $1 \mu \mathrm{g} / \mathrm{well}$ reporter plasmid vector (wild-type or mutant VEGF-A promoter-luciferase construct) and $50 \mathrm{ng} /$ well control vector (pGL4.7TK; Promega). After 24 hours of transfection, cells were washed three times with PBS, and cell lysates were prepared and subjected to luciferase assays. Luciferase activity was measured using a luminometer (Turner Biosystems, Sunnyvale, CA) and a Dual-Luciferase Reporter Assay System (Promega) according to the manufacturers' instructions. Data reflect the means $+\mathrm{SD}$ from three independent experiments performed in triplicate.

\section{Chromatin Immunoprecipitation}

Chromatin immunoprecipitation (ChIP) was performed using a ChIP kit (Upstate, Temecula, CA) according to the manufacturer's instructions with some modifications. Briefly, $1.0 \times 10^{6}$ TKB5pRevEGR-1 cells, in which EGR-1 was induced by doxycycline or not, were cross-linked by adding formaldehyde to the culture medium at a final concentration of $1 \%(\mathrm{v} / \mathrm{v})$. After fixation for 10 minutes, cells were washed twice with cold PBS containing protease inhibitors, and collected by centrifugation at $700 \mathrm{~g}$ for 5 minutes at $4^{\circ} \mathrm{C}$. Fixed cells were resuspended in SDS lysis buffer containing protease inhibitors, and the lysates were sonicated on ice until DNA fragments were $\sim 200-500$ bp in length. Samples were centrifuged at $13,300 \mathrm{~g}$ at $4^{\circ} \mathrm{C}$ for 10 minutes to remove insoluble material. The chromatin solution (supernatants) was precleaned by incubation with Protein $\mathrm{G}$ beads for 2 hours at 
$4^{\circ} \mathrm{C}$ and then incubated with $10 \mu \mathrm{g}$ rabbit polyclonal anti-EGR-1 (Santa Cruz Biotechnology), ${ }^{38}$ nonimmunized rabbit IgG (Santa Cruz Biotechnology), or rabbit polyclonal anti-HIF-1 $\alpha$ antibody (Santa Cruz Biotechnology). Antibody complexes were precipitated with Protein $G$ beads, washed with ChIP wash buffer, and eluted twice with $200 \mu \mathrm{l}$ elution buffer. Cross-linking was reversed by adding $4 \mu \mathrm{l} 5 \mathrm{~mol} / \mathrm{L} \mathrm{NaCl}$ and incubating at $65^{\circ} \mathrm{C}$ overnight. DNA was purified by incubation with proteinase $\mathrm{K}$ at $37^{\circ} \mathrm{C}$ for 2 hours, followed by phenol/ chloroform extraction and ethanol precipitation and then subjected to PCR amplification using a primer set designed to amplify VEGF-A promoter sequences containing the putative EGR-1-binding sites (Table 1).

\section{Electrophoretic Mobility Shift Assay}

To verify EGR-1 binding to the putative EGR-1-binding sites in the VEGF-A promoter, electrophoretic mobility shift assay (EMSA) reaction mixtures were prepared containing $2 \mu \mathrm{l}$ recombinant human EGR-1 protein (Alexis Biochemicals, Lausen, Switzerland) or $2 \mu \mathrm{g}$ of nuclear lysate from doxycycline-treated or -untreated TKB5pRevEGR-1, 1 pmol of the indicated digoxigenin-labeled double-stranded VEGF-A promoter-specific DNA probe, $20 \mathrm{mmol} / \mathrm{L}$ Tris$\mathrm{HCl}, \mathrm{pH} 7.9,50 \mathrm{mmol} / \mathrm{L} \mathrm{NaCl}, 1 \mathrm{mmol} / \mathrm{L}$ ethylenediaminetetraacetic acid, $5 \%$ glycerol, $1 \mu \mathrm{g}$ poly(dldC), and 5 $\mathrm{mmol} / \mathrm{L}$ dithiothreitol. The sense sequences of the double-stranded oligonucleotide probes were as follows: site 1, 5'-CAGAGTTTCCGGGGGCGGATGGGTA-3'; site 2-1, 5'-CCTGTCCCCGCCCCCCGGGGCGGGC-3'; site 2-2, 5'GGGCGGGCCGGGGGCGGGGTCCCG-3'; site 2-3, 5'GGGGTCCCGGGCGGGGCGGAGCCATG-3'; and site 2-4, 5'-GAGCCATGCGCCCCCCCCTTTTTTTT-3'. Reaction mixtures were incubated 30 minutes at $20^{\circ} \mathrm{C}$. Unlabeled double-stranded DNA probe containing the consensus EGR-1-binding sequence 5'-GCTCGCGGGGGCGATCGAAT-3' (sense strand) was used as a competitor. For antibody supershift experiments, rabbit polyclonal antiEGR-1 IgG (Santa Cruz Biotechnology) ${ }^{33}$ or rabbit polyclonal anti-HIF- $1 \alpha$ antibody (Santa Cruz Biotechnology) was added to reaction mixtures and incubated for 30 minutes at $4^{\circ} \mathrm{C}$. Reaction mixtures were then subjected to $5 \%(29: 1)$ native PAGE at $4^{\circ} \mathrm{C}$ in $0.25 \times$ TBE buffer for 3 hours at 150 $\checkmark$ with recirculating buffer. The protein-probe complexes were contact-blotted onto positively charged nylon membranes (Perkin-Elmer, Wellesley, MA) and fixed using UV light for 5 minutes. Digoxigenin-labeled probes were detected using a chemiluminescence detection kit according to the manufacturer's instructions (Roche Diagnostics, Mannheim, Germany).

\section{Tissues of Primary Lung Cancer Patients}

Primary lung adenocarcinoma tissues were surgically resected from 101 lung cancer patients consecutively treated at the Kanagawa Prefectural Cardiovascular and Respiratory Center Hospital. The institutional ethical boards of both Yokohama City University and Kanagawa Prefectural Cardiovascular and Respiratory Center Hospital approved this research. Informed consent was obtained from all subjects who provided materials for research use. Resected tissues were subjected to immunohistochemical analysis $(n=101)$, genotyping analysis of $K-R A S$ and EGFR genes $(n=64)$, and bisulfite sequencing analysis of NAB-2, EGR-1, and VEGF-A promoters $(n=10)$.

Approximately 1000 nuclei of cancer cells were microdissected from surgically resected, formalin-fixed, paraffin-embedded tumor sections of 64 adenocarcinomas using a laser capture microdissection system (PALMMBIII, Carl Zeiss, Munich, Germany) as described previously, ${ }^{36}$ and DNA was extracted by the phenol/chloroform method. For the detection of K-RAS codon 12 mutations, partially modified REMS-PCR ${ }^{42}$ was conducted as we reported previously. ${ }^{43}$ Fragments of EGFR (exon 19 and 21) were amplified by PCR and sequenced as described previously. ${ }^{43,44}$ Consequently, mutant $K$ RAS and mutant EGFR were detected in 15 and 12 adenocarcinomas, respectively. There was no adenocarcinoma carrying both K-RAS and EGFR mutations, as Kosaka et al reported. ${ }^{32}$

\section{Immunohistochemical Analysis of VEGF-A, EGR-1, NAB-2, NAB-1, and HIF-1 $\alpha$ Expression in Lung Cancer Tissues}

Histological diagnosis of lung adenocarcinomas was conducted according to the World Health Organization Classification. ${ }^{30}$ Formalin-fixed paraffin-embedded tumor sections of adenocarcinomas were stained with hematoxylin and eosin (H\&E) or immunostained. Immunostain was conducted using an EnVision Plus System-HRP kit (DAKO, Carpinteria, CA) and the following primary antibodies: rabbit polyclonal anti-VEGF-A (1:200, Santa Cruz Biotechnology), ${ }^{40}$ rabbit polyclonal anti-EGR-1 (1:2000, Santa Cruz Biotechnology), ${ }^{38}$ mouse monoclonal anti-HIF-1 $\alpha$ (1:100, Santa Cruz Biotechnology), ${ }^{39}$ mouse monoclonal antiNAB-2 (1:200, Santa Cruz Biotechnology), ${ }^{41}$ or rabbit polyclonal anti-NAB-1 (1:500, AVIVA Systems Biology). ${ }^{26} \mathrm{Be}-$ fore immunostaining, deparaffinized and rehydrated tissue sections were microwaved in sodium citrate buffer $(\mathrm{pH}$ 6.0) for 20 minutes to restore antigenicity. Tissue sections were incubated with primary antibodies overnight at $4^{\circ} \mathrm{C}$. As negative staining controls, the primary antibodies were replaced with the Primary Antibody Diluent (DAKO). Human placental tissues were used as a positive control for $\mathrm{HIF}-1 \alpha$ staining, and formalin-fixed paraffin-embedded A549 cells, which expressed VEGF-A, EGR-1, NAB-2, and NAB-1 as shown in Figure $1 A$, were used as positive controls for VEGF-A, EGR-1, NAB-2, and NAB-1 staining. Immunostaining was detected using the HRP-labeled secondary antibodies and diaminobenzidine (DAB) provided in the kit, and nuclei were counterstained with hematoxylin. Expression of each antigen was semiquantitatively scored according to the method by Sun et al. ${ }^{45}$ Expression scores were calculated by multiplying the percentage of immunopositive cancer cells per section by the relative immunohistochemical staining intensity (scored as 0 , negative; 1 , weak; 2 , intermediate; and 3, intense). Therefore, expression scores ranged from 0 to 300. Median ES of 101 adenocarcinomas 
A

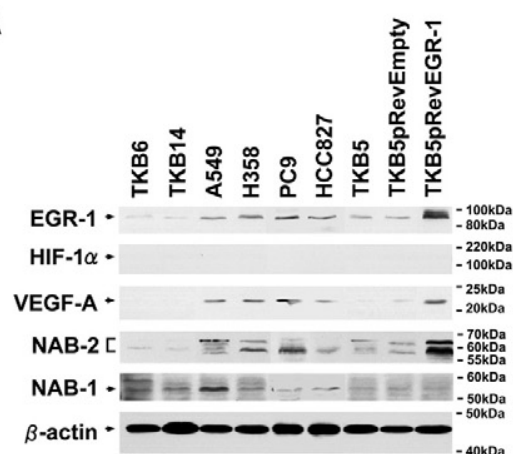

B
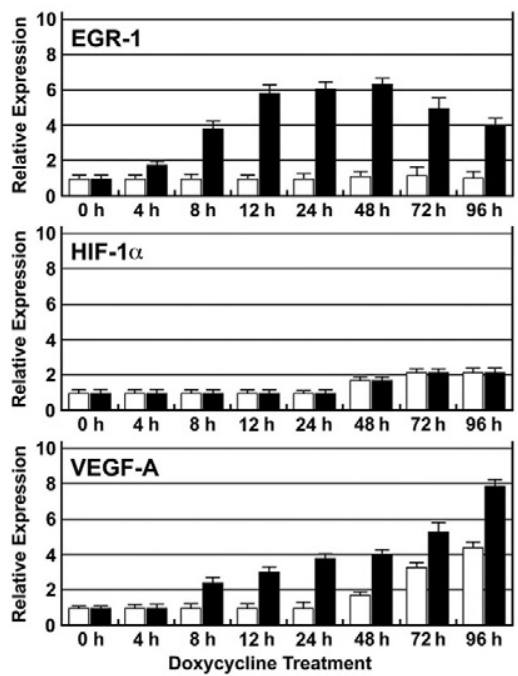

C

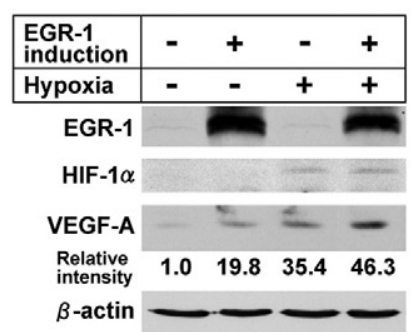

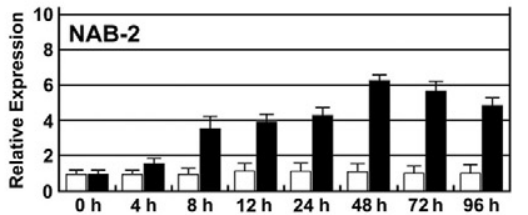

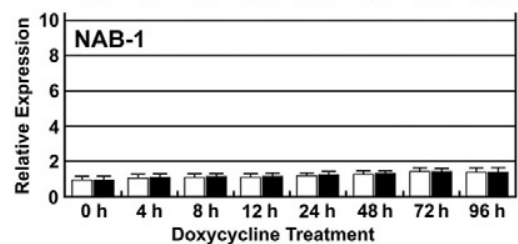

Doxycycline Treatment

D

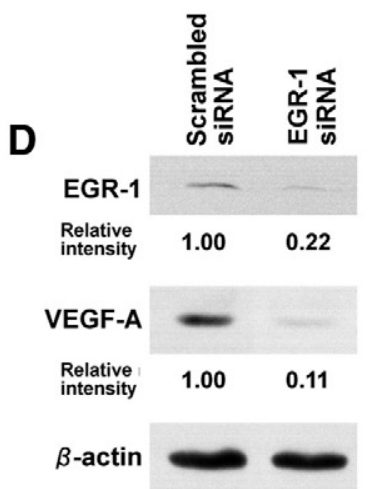

Figure 1. Analysis of EGR-1, HIF-1 $\alpha$, VEGF-A, NAB-2, and NAB-1 expression in cultivated lung cancer cells. A: Western blot analysis of whole-cell lysates from adenocarcinoma cell lines containing wild-type $K$-RAS and EGFR (TKB6 and TKB14), mutant K-RAS (A549, H358), or mutant EGFR (PC9 and HCC827) and from control and EGR-1-transfected TKB5 cells (TKB5pRevEmpty and TKB5pRevEGR-1) and their parental cells (TKB5). Lysates were separated by SDS-PAGE and immunoblotted using antibodies against the proteins indicated. $\beta$-Actin was analyzed as an internal control. Lung cancer cells without mutation of $K$-RAS/EGFR expressed minimal amounts of EGR-1, NAB-2, and VEGF-A, whereas these proteins were readily detectable in mutant $K$-RAS-carrying cells (A549 and H358) and mutant EGFR-carrying cells (PC9 and HCC827). EGR-1 was abundantly induced by doxycycline treatment for 24 hours in TKB5pRevEGR-1 cells, and NAB-2 and VEGF-A were also promptly induced by EGR-1 induction. NAB-1 was constitutively expressed, but HIF-1 $\alpha$ was not detectable in all cell lines. B: Quantitative RT-PCR (qRT-PCR) analysis in TKB5pRevEmpty cells (open bars) and TKB5pRevEGR-1 cells (closed bars) after doxycycline treatment for the indicated times. HIF-1 $\alpha$ expression weakly increased after 48 hours, irrespective of EGR-1 induction. However, EGR-1 induction by doxycycline treatment ( $1 \mu \mathrm{g} / \mathrm{ml}$ final concentration) up-regulated VEGF-A expression, and the expression levels of TKB5pRevEGR-1 cells (72 hours and 96 hours) were further increasing and much higher than those of TKB5pRevEmpty cells. NAB-2 was promptly induced by EGR-1, whereas NAB-1 expression was not altered. C: Association of VEGF-A expression with EGR-1 and HIF-1 $\alpha$. TKB5pRevEGR-1 cells were cultivated in the hypoxic condition $\left(0.5 \% \mathrm{O}_{2}\right.$ and $\left.5 \% \mathrm{CO}_{2}\right)$ for eight hours. Doxycycline $(1 \mu \mathrm{g} / \mathrm{ml}$ final concentration) was added 24 hours before harvest. Lysates were separated by SDS-PAGE and immunoblotted using antibodies against the proteins indicated. $\beta$-Actin served as an internal control. Relative expression level of VEGF-A was calculated as follows: (intensity of VEGF-A/intensity of $\beta$-actin)/[intensity of VEGF-A (no EGR-1 induction and no hypoxic culture)/intensity of $\beta$-actin (no EGR-1 induction and no hypoxic culture)]. VEGF-A was not only induced by EGR-1 and HIF-1 $\alpha$ but also enhanced by coexpression of EGR-1 and HIF-1 $\alpha$. D: Alteration of VEGF-A expression by forced repression of EGR-1 in H358 cells. The EGR-1-specific or scrambled control siRNA was treated on H358 cells for 24 hours. $\beta$-Actin served as an internal control. Relative expression levels of EGR-1 and VEGF-A were calculated as follows: (intensity of EGR-1 or VEGF-A/intensity of $\beta$-actin)/[intensity of EGR-1 or VEGF-A (scrambled siRNA)/intensity of $\beta$-actin (scrambled siRNA)]. The VEGF-A expression decreased by EGR-1 repression.

were used as the cut-off score between high and low expression scores. Median expression scores of VEGF-A, EGR-1, HIF-1 $\alpha$, NAB-2, and NAB-1 were 154.0, 126.3, 104.2, 48.4, and 90.1, respectively. To investigate the association of VEGF-A, EGR-1, HIF- $1 \alpha$, NAB-2, and NAB-1 expression with histological differentiation, adenocarcinomas were classified as well differentiated (mainly having bronchoalveolar growth; $n=39$ ), moderately differentiated (mainly having acinar or papillary growth; $n=48$ ), or poorly differentiated (mainly having solid growth; $n=14$ ), based on morphological criteria.

\section{Bisulfite Sequencing of NAB-2, EGR-1, and VEGF-A Promoters}

DNA from surgically resected or cultivated lung cancer cells was extracted by the phenol/chloroform method and then treated with sodium bisulfite using a MethylEasy DNA bisulfite modification kit (Human Genetic Signatures, Macquarie Park, Australia) as described previously. ${ }^{23}$ The NAB-2, EGR-1, and VEGF-A promoter-specific primers for bisulfite sequencing were constructed using promoter sequence data and primer design software (OLIGO 6.9: Molecular Biology Insight, Cascade, CO), and the primer sequences are shown in Table 1. PCR was conducted using HotStarTaq DNA polymerase (Qiagen, Hilden, Germany). The PCR products were purified and ligated into the pT7Blue vector (Novagen), and at least five separate clones each were chosen for sequence analysis.

\section{Treatment with 5-Aza-2'-Deoxycytidine}

Cultivated lung cancer cells were treated either with 10 $\mathrm{nmol} / \mathrm{ml}$ of 5-aza-2'-deoxycytidine (AZA, Wako, Osaka, 
Japan) for 72 hours by exchanging the medium everyday or with $300 \mathrm{ng} / \mathrm{ml}$ of trichostatin A (TSA, Wako) for 24 hours. In addition, cells were also treated with AZA for 48 hours and then with a combination of AZA and TSA for an additional 24 hours.

\section{Statistical Analysis}

The relationships of expression scores between EGR-1 and VEGF-A, between HIF- $1 \alpha$ and VEGF-A, between EGR-1 and NAB-2, and between EGR-1 and HIF- $1 \alpha$ were analyzed using Pearson's correlation coefficient test. The expression scores were compared in adenocarcinomas with mutant $K$-RAS and those without $K$-RAS/EGFR mutation or in adenocarcinomas with mutant EGFR and those without $K-R A S / E G F R$ mutation, using the Mann-Whitney $U$ test. The expression scores were also compared in poor, moderate, and well-differentiated adenocarcinomas using the one-way analysis of variance. Statistical significance was set at $P<0.05$.

\section{Results}

\section{EGR-1 Upregulates VEGF-A Expression in Lung Cancer Cells}

We examined the expression of EGR-1, HIF- $1 \alpha$, VEGF-A, NAB-2, and NAB-1 in lung cancer cells cultivated under ordinary maintenance conditions by Western blot analysis (Figure 1A). TKB6 and TKB14 adenocarcinoma cell lines, which lack the K-RAS and EGFR mutations, expressed minimal amounts of EGR-1, VEGF-A, and NAB-2, whereas these proteins were readily detectable in A549 and H358 adenocarcinoma cell lines, which carry the K-RAS mutation and in PC9 and HCC827 adenocarcinoma cell lines, which carry the EGFR mutation. In the TKB5 large-cell carcinoma cell line, the expression levels of EGR-1 and NAB-2 were lower than in adenocarcinoma cell lines carrying mutant K-RAS/VEGFR (A549, H358, PC9, and HCC827), and the VEGF-A signal was negligible. However, EGR-1 expression was induced robustly in TKB5pRevEGR-1 cells after doxycycline treatment for 24 hours, and VEGF-A and NAB-2 were up-regulated in EGR-1-induced TKB5pRevEGR-1 cells. HIF-1 $\alpha$ expression was not detected in any of the lung cancer cells cultivated under ordinary maintenance conditions, and NAB-1 was constitutively expressed in all cell lines examined, as reported previously. ${ }^{28}$

Next, we investigated temporal alterations of VEGF-A, NAB-2, NAB-1, and HIF- $1 \alpha$ expression in association with EGR-1 induction using qRT-PCR analysis of TKB5pRevEGR-1 and TKB5pRevEmpty cells. As shown in Figure 1B, an increase in EGR-1 mRNA in TKB5pRevEGR-1 cells was found 4 hours after induction by addition of doxycycline, peaked at 48 hours after induction ( $\sim 6$-fold increase relative to TKB5pRevEmpty cells), and then gradually declined. EGR-1 expression was unchanged in TKB5pRevEmpty cells throughout the culture period. VEGF-A mRNA expression in TKB5pRevEGR-1 cells gradually increased between 8 hours and 96 hours ( 8 -fold increase relative to untreated cells). However, the VEGF-A mRNA in TKB5pRevEmpty cells also increased beginning at 48 hours, increasing $\sim$ three- and fourfold compared with untreated cells at 72 and 96 hours, respectively, despite the absence of EGR-1 induction. And the results of qRT-PCR showed an approximately twofold increase of HIF-1 $\alpha$ expression both in TKB5pRevEmpty and TKB5pRevEGR-1 cells at 48 to 96 hours. These findings indicated the association of HIF- $1 \alpha$ in VEGF-A expression. NAB-2 expression increased in conjunction with EGR-1 induction, whereas $N A B-1$ expression remained unchanged, as reported previously. 28,29

To examine whether EGR-1 and HIF- $1 \alpha$ cooperatively induce VEGF-A expression, we next investigated the relationships among EGR-1, HIF- $1 \alpha$, and VEGF-A expression in EGR-1-induced or EGR-1-uninduced TKB5pRevEGR-1 cells cultured under hypoxic conditions using Western blot analysis. As shown in Figure $1 C$, under the ordinary maintenance conditions, the VEGF-A expression level in EGR1-induced TKB5pRevEGR-1 cells increased approximately 19.8-fold in comparison with EGR-1-uninduced TKB5pRevEGR-1 cells. The HIF- $1 \alpha$ protein was apparently induced by culture under hypoxic conditions for 8 hours, and the signal intensity of EGR-1-induced and EGR-1uninduced TKB5pRevEGR-1 cells increased approximately 35.4-fold and 46.3-fold, respectively. These findings suggested that both EGR-1 and HIF-1 $\alpha$ upregulate VEGF-A expression and that EGR-1 enhances HIF- $1 \alpha$-induced VEGF-A expression.

To confirm close association of EGR-1 with VEGF-A expression, we next conducted an RNA interference experiment. As shown in Figure 1D, a siRNA targeted to EGR-1 promptly repressed VEGF-A expression.

\section{EGR-1 Activates VEGF-A by Binding to the VEGF-A Promoter}

To understand how EGR-1 is associated with VEGF-A activation in lung cancer cells, we conducted VEGF-A promoter assay experiments. A reporter construct in which luciferase expression is driven by the full-length VEGF-A promoter was transfected into TKB5pRevEGR-1 and TKB5pRevEmpty cells, and cells were grown in the absence or presence of doxycycline. As shown in Figure 2A (top), doxycycline-mediated EGR-1 induction enhanced luciferase activity threefold in TKB5pRevEGR-1 cells but not control cells. This result suggests that EGR-1 is closely associated with VEGF-A gene activation.

Next, we searched for putative EGR-1-binding sites in the VEGF-A promoter using computer software (MatInspector: Genomatix, Muenchen, Germany). As shown in the bottom panel of Figure 2A, we identified five putative EGR1-binding sites (one between $\mathrm{nt}-247$ and -231 and the others between nt -98 and -32 from the transcription start site). From these, we generated VEGF-A promoter deletion or mutation reporter constructs and examined the resulting luciferase activity in doxycycline-treated TKB5pRevEGR-1 cells. As shown in Figure 2A (bottom), deletion of the HIF$1 \alpha$-binding site ${ }^{46}$ did not significantly alter VEGF-A promoter activity, consistent with the observation that $\mathrm{HIF-1} \alpha$ 


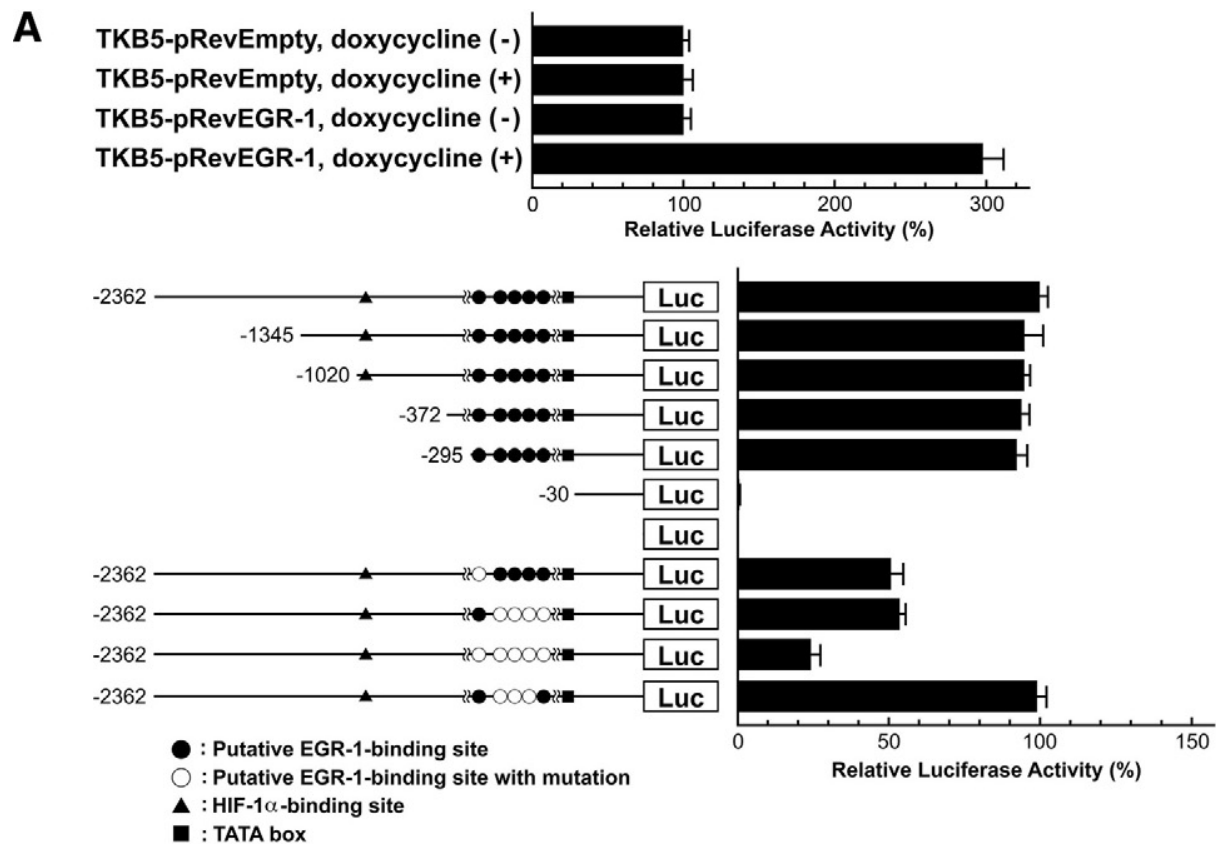

B

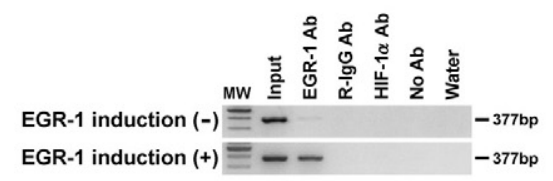

C

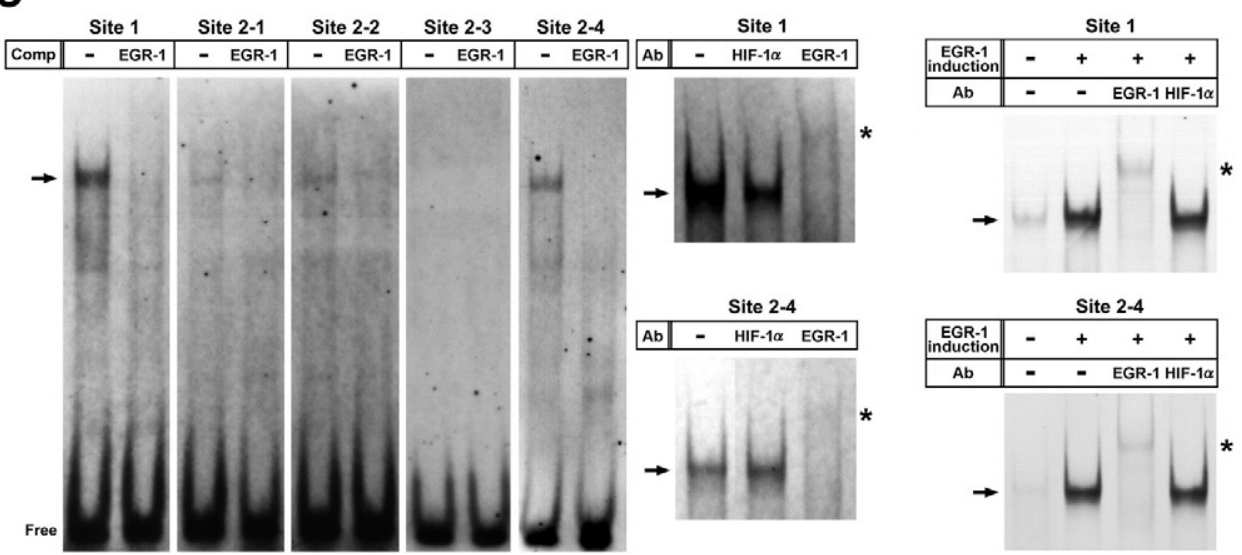

Figure 2. EGR-1 binds to the $V E G F-A$ promoter and activates gene expression. A: $V E G F-A$ promoter assays. Top: TKB5pRevEmpty or TKB5pRevEGR-1 cells were transiently cotransfected with full-length $V E G F-A$ promoter-luciferase reporter construct and control vector for 24 hours with or without doxycycline treatment, and the cells were harvested, lysed, and subjected to luciferase assays. Data reflect means + SD from three experiments performed in triplicate. The mean luciferase activity of full-length VEGF-A promoter in TKB5-pRevEmpty without doxycycline treatment is set to $100 \%$. Bottom: TKB5pRevEGR-1 cells were transiently transfected with wild-type $V E G F-A$ promoter-luciferase reporter construct or the indicated $V E G F-A$ promoter deletion or mutation construct for 24 hours in the presence of doxycycline, and the cells were harvested, lysed, and subjected to luciferase assays. Data reflect the means + SD from three experiments performed in triplicate. The mean luciferase activity of full-length VEGF- $A$ promoter in TKB5-pRevEGR-1 is set to $100 \%$. B: ChIP-based PCR analysis using doxycycline-treated or untreated TKB5pRevEGR-1 cells. DNA fragments conjugated with nuclear proteins were immunoprecipitated with rabbit anti-EGR-1, nonimmunized rabbit IgG, or rabbit anti-HIF-1 $\alpha$ antibody. Immunoprecipitated DNA was PCR-amplified using primers for a $377-$ bp fragment containing the putative EGR-1-binding sites (Table 1) and then separated by agarose gel electrophoresis. Input indicates input DNA; water, no DNA. Weak signal was amplified from the EGR-1 immunoprecipitates even in the condition of no EGR-1 induction (top). This result was consistent with the fact that TKB5pRevEGR-1 constitutively expressed low level of EGR-1-like parental TKB5 cells (Figure 1A). The specific signal was abundantly amplified by EGR-1 induction (bottom). C: EMSA analysis using recombinant EGR-1 (left) and nuclear lysates from TKB5pRevEGR-1 with or without EGR-1 induction (right). Left: Recombinant EGR-1 was incubated with the indicated digoxigenin-labeled EGR-1-binding site probe with or without unlabeled competitor probe (100-fold molar excess) for the consensus EGR-1-binding motif 5'-GCGGGGGCG-3'. EGR-1 bound with highest affinity to sites 1 and 2-4 (arrow). Left, insets: Recombinant EGR-1 was incubated with the indicated digoxigenin-labeled EGR-1-binding site 1 (top) or site 2-4 (bottom) probe with the indicated antibody. Right: Nuclear lysates extracted from EGR-1-induced or uninduced TKB5pRevEGR-1 cells was incubated with the indicated digoxigenin-labeled EGR-1-binding site 1 (top) or site 2-4 (bottom) probe with the indicated antibody. Abundant EGR-1-specific complex was formed by EGR-1 induction and the signal supershifted by anti-EGR-1 antibody. Arrow, EGR-1specific signal; asterisk, Supershifted EGR-1-specific signal. 
A

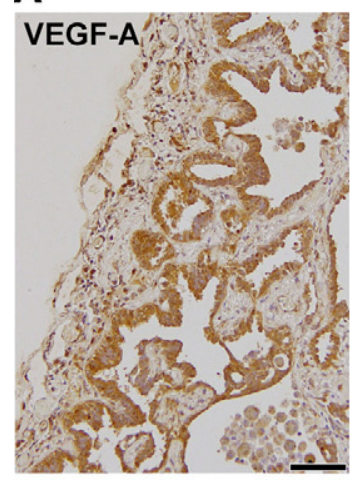

B

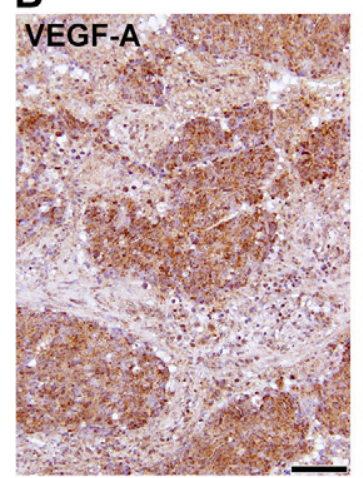

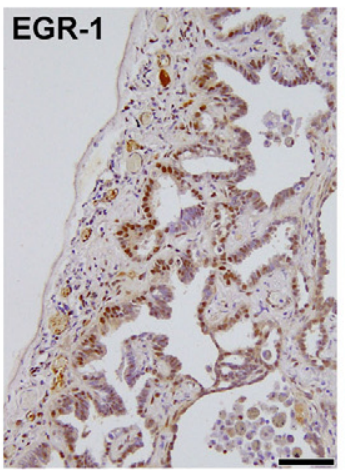
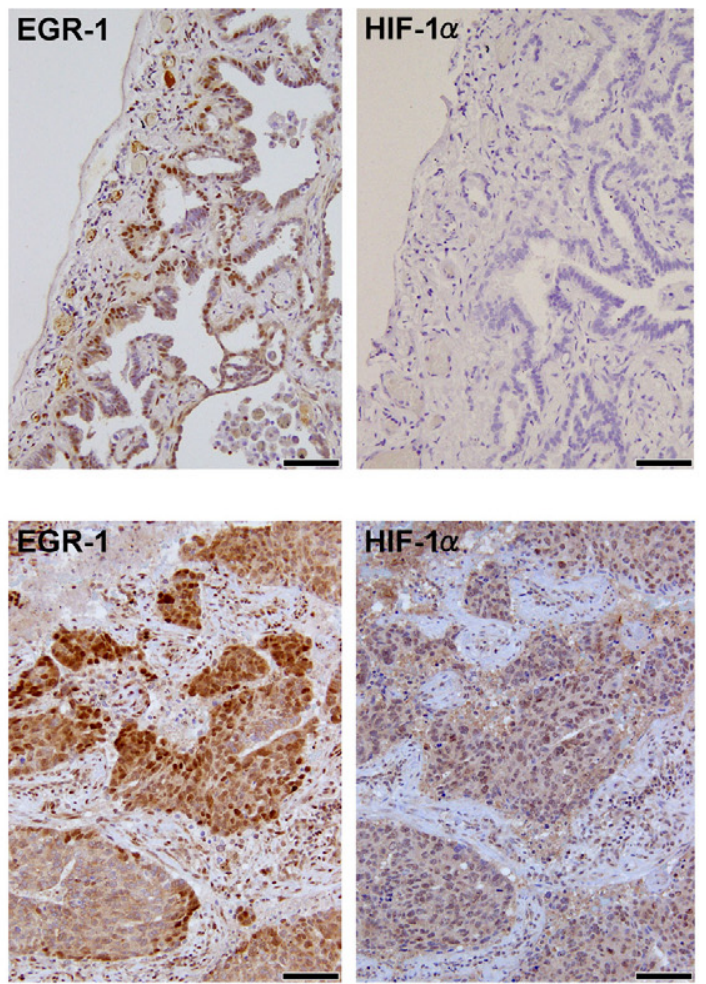

C
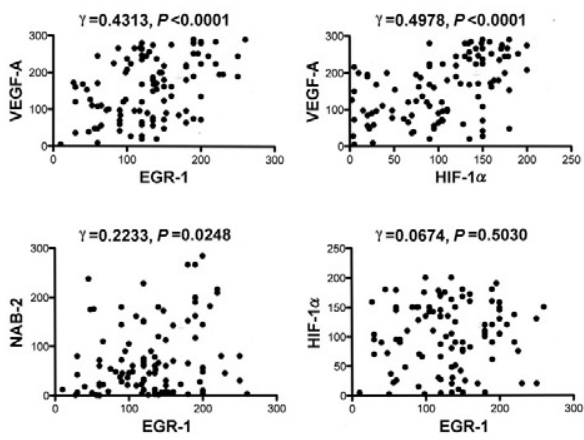

Figure 3. Immunohistochemistry of VEGF-A, EGR-1, and HIF- $1 \alpha$ expression in surgically resected lung adenocarcinomas. Representative images are shown. A: In a well-differentiated adenocarcinoma, VEGF-A expression is diffuse in the cytoplasm, and EGR-1 is highly expressed in nuclei; HIF- $1 \alpha$ is not expressed. B: In a poorly-differentiated adenocarcinoma, VEGF-A expression is diffuse in the cytoplasm, and EGR-1 and HIF- $1 \alpha$ are both primarily expressed in nuclei. Scale bars $=100 \mu \mathrm{m}$. C: Relationships between EGR-1 and VEGF-A, between HIF- $1 \alpha$ and VEGF-A, between EGR-1 and NAB-2, and between EGR-1 and HIF- $1 \alpha$ (Pearson's correlation coefficient test). The expression score (ES) of EGR-1 was correlated with that of VEGF-A and $\mathrm{NAB}-2$, and the ES of HIF- $1 \alpha$ was also correlated with that of VEGF-A. However, there was no correlation between EGR-1 and HIF-1 $\alpha$. expression is negligible in lung cancer cells cultivated under ordinary maintenance conditions (Figure 1A). In contrast, mutation of EGR-1-binding site 1 or all four binding sequences within site 2 resulted in a $50 \%$ decline in promoter activity, and mutation of all five binding sites resulted in an $80 \%$ decline in promoter activity.

To verify that EGR-1 binds to the putative EGR-1-binding sites, we performed ChIP-based PCR analysis using nuclear lysates from EGR-1-induced and EGR-1-uninduced TKB5 cells and a primer set specific for the putative EGR$1-$ binding region in the VEGF-A promoter. This analysis confirmed that EGR-1 binds to the putative EGR-1-binding region in the VEGF-A promoter (Figure $2 \mathrm{~B}$ ).

We next conducted EMSAs to examine to which putative binding sites within the VEGF-A promoter EGR-1 bind. As shown in Figure 2C (left), the EGR-1 binding affinities were quite different among the putative EGR-1-binding sites; the affinity at sites 1 and 2-4 was substantially higher than at site 2-1, 2-2, or 2-3. And recombinant EGR-1-probe conjugates were supershifted by supplementation with anti-EGR-1 antibody (Figure 2C, left). Significantly, these binding data are consistent with the luciferase promoter assays, in which mutations in sites 2-1, 2-2, plus 2-3 resulted in a wild-type level of promoter activity, while mutations in sites 1 and 2-4 acted both alone and cooperatively to reduce promoter activity (Figure 2A, bottom). The specific signals were also detected in EMSA using nuclear lysates extracted from TKB5pRevEGR-1 cells (Figure 2C, right). The signal intensities increased by EGR-1 induction, and the specificity was confirmed by supershift assay. These findings suggested that EGR-1 plays a crucial role in VEGF-A induction by binding to the VEGF-A promoter, and that EGR-1-binding sites 1 and 2-4 are particularly important for EGR-1mediated VEGF-A induction.

\section{VEGF-A Expression and Its Relationship to EGR-1, NAB-2, NAB-1, and HIF-1 $\alpha$ in Surgically Resected Lung Adenocarcinomas}

Our in vitro experiments indicated that EGR-1 directly facilitates VEGF-A expression, that HIF-1 $\alpha$ induces VEGF-A expression in lung cancer cells exposed to hypoxic conditions, and that EGR-1 and HIF-1 $\alpha$ cooperatively induce VEGF-A. Therefore, to confirm consistency between the in vitro results and in vivo findings, we next investigated the expression of VEGF-A and its relationship to EGR-1, HIF-1 $\alpha$, NAB-2, and NAB-1 in surgically resected lung adenocarcinoma tissues.

VEGF-A expression was observed in EGR-1-expressing adenocarcinoma cells despite a lack of HIF- $1 \alpha$ expression (Figure 3A). Furthermore, HIF- $1 \alpha$-expressing adenocarcinomas that had high EGR-1 expression scores often also exhibited robust VEGF-A expression (Figure 3B). As shown in Figure 3C, the expression scores of EGR-1 were correlated with those of VEGF-A $(\gamma=0.4313, P<0.0001)$, and the expression scores of HIF- $1 \alpha$ were also correlated with VEGF-A ( $\gamma=0.4978$, $P<0.0001)$. Furthermore, the expression scores of EGR-1 were weakly correlated with NAB-2 ( $\gamma=0.2233$, $P=0.0248)$. However, correlation was not found between EGR-1 and HIF-1 $\alpha$ expression $(\gamma=0.0674, P=$ 0.5030). 
Table 2. Association of K-RAS/EGFR Mutation with Expression Scores of EGR-1, HIF- $1 \alpha$, or VEGF-A in Surgically Resected Lung Adenocarcinomas

\begin{tabular}{lcccc}
\hline & \multicolumn{3}{c}{ K-RAS/EGFR gene mutation } \\
\cline { 2 - 5 } Antigen & K-RAS $(n=15)$ & EGFR $(n=12)$ & None $(n=37)$ & $P^{*}$ \\
\hline EGR-1 & $148.1 \pm 55.7$ & $123.0 \pm 59.1$ & $109.8 \pm 53.5$ & 0.0802 (K-RASversus None) \\
HIF-1 $\alpha$ & $84.0 \pm 58.3$ & $101.8 \pm 49.1$ & $100.0 \pm 53.2$ & 0.8522 (EGFR versus None) \\
VEGF-A & $170.8 \pm 66.9$ & $155.3 \pm 88.2$ & $133.7 \pm 81.3$ & 0.9443 (K-RASversus None) \\
& & & 0.1151 (K-RASversus None) \\
& & & 0.5001 (EGFR versus None) \\
\hline
\end{tabular}

Expression scores were calculated as described in Materials and Methods. Data reflect means \pm SD. There was no case carrying both K-RAS and EGFR mutations.

*Mann-Whitney $U$ test.

Next, we examined the association of K-RAS/EGFR mutations with expression of EGR-1, HIF-1 $\alpha$, and VEGF-A in surgically resected lung adenocarcinomas. The average expression scores of EGR-1 and VEGF-A in K-RASor EGFR-mutated adenocarcinomas were modestly high in comparison with adenocarcinomas carrying wild-type K-RAS and EGFR genes (Table 2). However, no statistically significant differences of EGR-1, HIF-1 $\alpha$, and VEGF-A expressions were found among those three groups.

As shown in Table 3, the VEGF-A and EGR-1 expression scores in lung adenocarcinoma cells significantly increased as tumors dedifferentiated $(P=0.0014$ and $P=0.0294$, respectively). The proportion of tumors with high VEGF-A expression scores and high EGR-1 expression scores increased as tumors dedifferentiated. However, HIF-1 $\alpha$ expression is apparently independent of tumor differentiation, as approximately $50 \%$ of tumors in all groups had high HIF- $1 \alpha$ expression scores. HIF- $1 \alpha$, NAB-2, and NAB-1 expression scores revealed no significant differences among histologic differentiation $(P=$ $0.8777, P=0.3138$, and $P=0.4054$, respectively).

Although the expression scores of EGR-1 were weakly correlated with NAB-2 (Figure 3C), NAB-2 expression in lung adenocarcinoma cells rather decreased with dedifferentiation in contrast to VEGF-A and EGR-1 (Table 3). Because NAB-2 is induced by, binds to, and represses the function of EGR-1, ${ }^{26,28}$ our findings indicated a possibility that deregulation of the NAB-2/EGR-1 feedback loop is associated with VEGF-A expression in adenocarcinoma cells in vivo. Because the NAB-2, EGR-1, and VEGF-A gene promoters contain $\mathrm{CpG}$ islands (Figure $4 \mathrm{~A})$, we finally investigated whether the dissociation between EGR-1 and NAB-2 expression in surgically re-

Table 3. Expression Scores of VEGF-A, EGR-1, NAB-2, NAB-1, and HIF-1 $\alpha$ in Surgically Resected Lung Adenocarcinomas

\begin{tabular}{|c|c|c|c|c|}
\hline \multirow[b]{2}{*}{ Antigen } & \multicolumn{4}{|c|}{ Histological differentiation } \\
\hline & WELL $(n=39)$ & $\operatorname{MOD}(n=48)$ & $\operatorname{POOR}(n=14)$ & $P^{*}$ \\
\hline \multicolumn{5}{|l|}{ VEGF-A } \\
\hline Mean $\pm \mathrm{SD}$ & $117.2 \pm 78.9$ & $179.5 \pm 78.2$ & $189.5 \pm 77.4$ & 0.0014 \\
\hline Range & 5.0-280.0 & 27.5-290.0 & 64.0-290.0 & \\
\hline High ES [n (\%)] & $15(38 \%)$ & $29(60 \%)$ & $9(64 \%)$ & \\
\hline Low ES $[n(\%)]$ & $24(62 \%)$ & $19(40 \%)$ & $5(36 \%)$ & \\
\hline \multicolumn{5}{|l|}{ EGR-1 } \\
\hline Mean $\pm S D$ & $113.8 \pm 52.5$ & $132.1 \pm 51.5$ & $154.9 \pm 66.9$ & 0.0294 \\
\hline Range & 40.0-200.0 & 27.5-250.0 & 50.0-260.0 & \\
\hline High ES [n (\%)] & $18(46 \%)$ & $25(52 \%)$ & $10(71 \%)$ & \\
\hline Low ES $[n(\%)]$ & $21(54 \%)$ & $23(48 \%)$ & $4(29 \%)$ & \\
\hline \multicolumn{5}{|l|}{ HIF-1 $\alpha$} \\
\hline Mean \pm SD & $105.7 \pm 50.7$ & $101.3 \pm 57.1$ & $96.3 \pm 67.6$ & 0.8777 \\
\hline Range & $5.0-180.0$ & $2.5-190.0$ & $2.5-200.0$ & \\
\hline High ES [n (\%)] & $22(56 \%)$ & $25(52 \%)$ & $7(50 \%)$ & \\
\hline Low ES $[n(\%)]$ & $17(44 \%)$ & $23(48 \%)$ & $7(50 \%)$ & \\
\hline \multicolumn{5}{|l|}{ NAB-2 } \\
\hline Mean \pm SD & $90.4 \pm 80.6$ & $66.3 \pm 65.9$ & $67.1 \pm 68.0$ & 0.3138 \\
\hline Range & $1.0-284.2$ & 1.0-228.0 & $2.4-190.0$ & \\
\hline High ES $[n(\%)]$ & $23(59 \%)$ & $25(52 \%)$ & $7(50 \%)$ & \\
\hline Low ES $[n(\%)]$ & $16(41 \%)$ & $23(48 \%)$ & $7(50 \%)$ & \\
\hline \multicolumn{5}{|l|}{ NAB-1 } \\
\hline Mean $\pm S D$ & $109 \pm 72.9$ & $107.2 \pm 62.6$ & $112.9 \pm 85.4$ & 0.4054 \\
\hline Range & $2.5-200.0$ & 2.5-230.0 & $44.0-238.0$ & \\
\hline High ES $[n(\%)]$ & $17(44 \%)$ & $28(58 \%)$ & $7(50 \%)$ & \\
\hline Low ES [n (\%)] & $22(56 \%)$ & 20 (42\%) & $7(50 \%)$ & \\
\hline
\end{tabular}

Expression scores (ES) were calculated as described in Materials and Methods. Median ES of 101 adenocarcinomas were used as the cut-off between high and low ES. Median ES of VEGF-A, EGR-1, HIF-1 $\alpha$, NAB-2, and NAB-1 were 154.0, 126.3, 104.2, 48.4, and 90.1, respectively.

WELL indicates well differentiated; MOD, moderately differentiated; POOR, poorly differentiated.

*One-way ANOVA. 
A
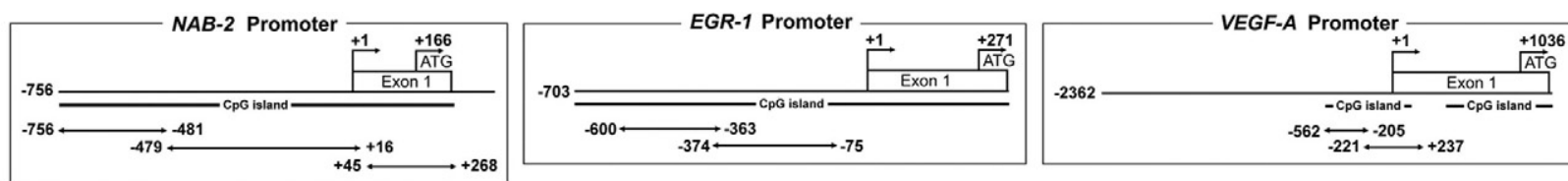

B

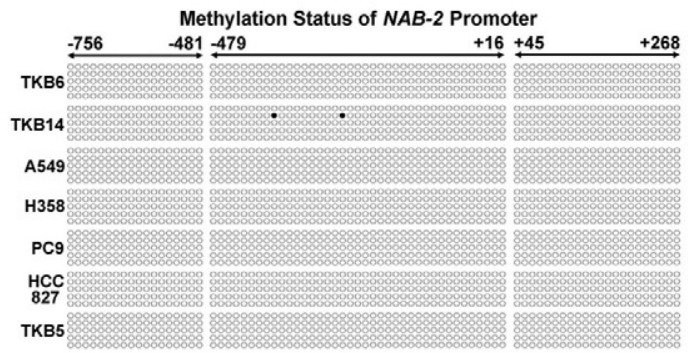

C
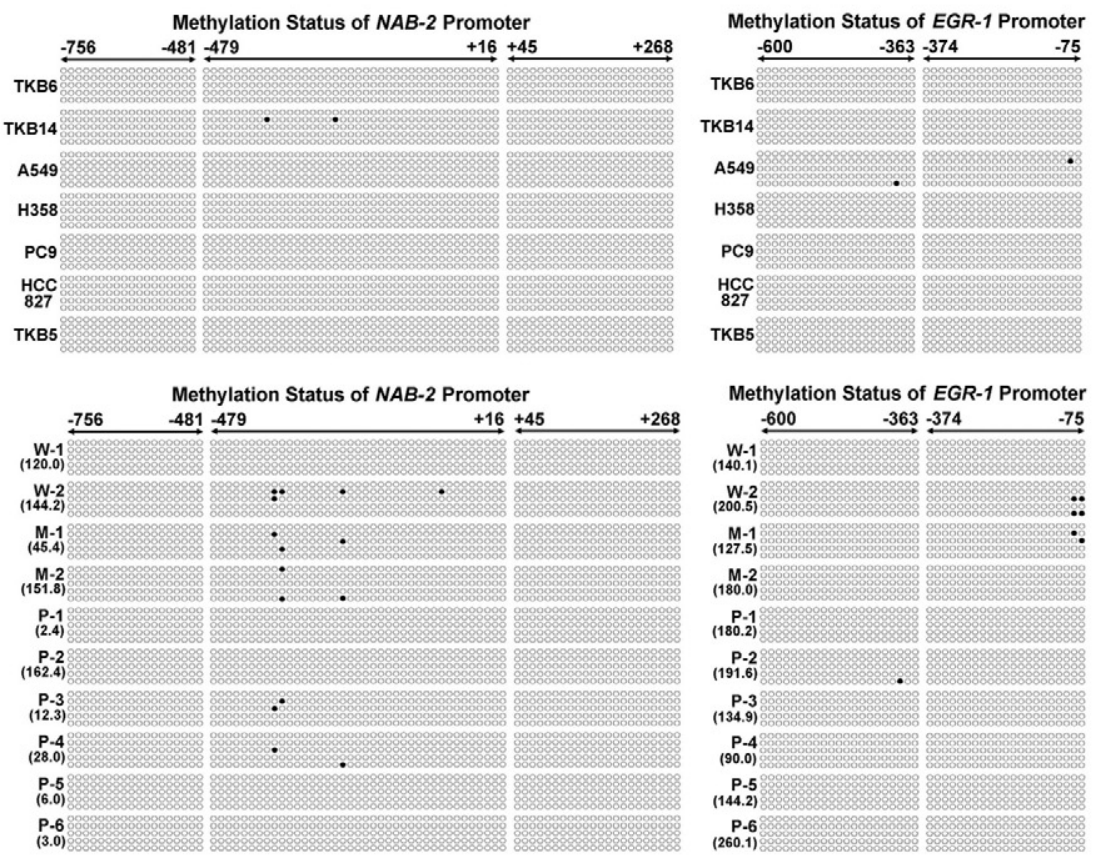

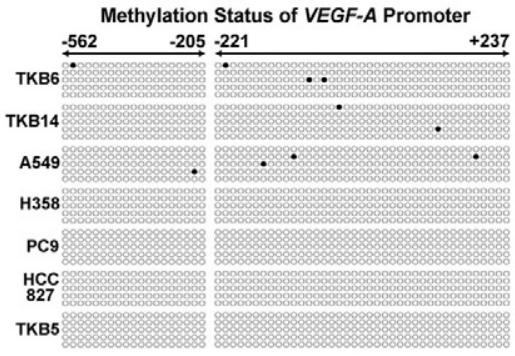

Methylation Status of VEGF-A Promoter

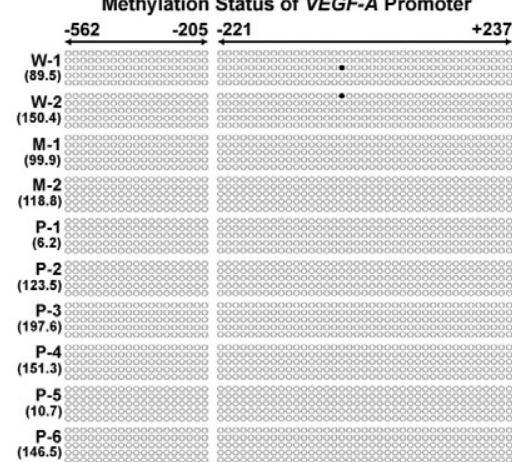

D

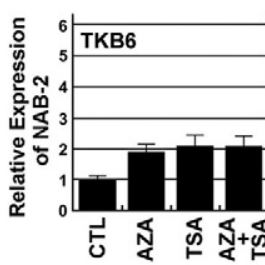

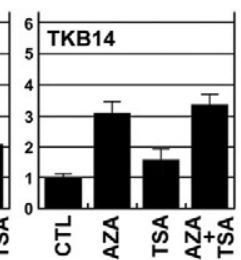
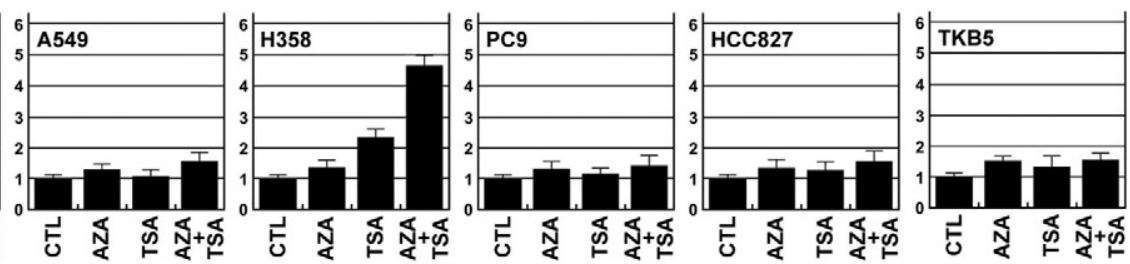

Figure 4. NAB-2, EGR-1, and $V E G F-A$ promoter $\mathrm{CpG}$ islands are not hypermethylated in lung cancer cells. A: Localization of CpG islands and regions subjected to bisulfite-modified DNA sequencing (BS). Nucleotide positions are relative to the transcription start site. B and C: Summary of BS analysis of $N A B-2, E G R-1$, and $V E G F-A$ promoter methylation using bisulfite-modified DNA extracted from cultivated lung cancer cells (B) and in vivo adenocarcinoma cells (C). Nucleotide positions are relative to the transcription start site. Closed circle indicates methylated CpG site; open circle, unmethylated CpG site. No severe methylation was noted in $N A B-2, E G R-1$, or VEGF-A promoters of all cell lines and in vivo adenocarcinoma cells examined. Parenthesis indicates the expression score of each case. W1-W2, M1-M2, and P1-P6 indicated well-differentiated (W), moderately differentiated (M), and poorly differentiated (P) adenocarcinoma samples, respectively. D: Alteration of NAB-2 expression via 5-aza-2'-deoxycytidine treatment in cultivated lung cancer cells. Cells were treated with $10 \mathrm{nmol} / \mathrm{ml}$ of 5 -aza-2'deoxycytidine (AZA) for 72 hours or with $300 \mathrm{ng} / \mathrm{ml}$ of trichostatin A (TSA) for 24 hours. In addition, cells were also treated with AZA for 48 hours and then with a combination of AZA and TSA for an additional 24 hours. Apparent increase of NAB-2 expression was found in TKB6, TKB14, and H358 cells through the AZA and/or TSA treatment.

sected lung adenocarcinoma cells was caused by epigenetic silencing. Consequently, we could obtain bisulfite sequence data of seven lung cancer cell lines and 10 adenocarcinomas ( 2 well differentiated, 2 moderately differentiated, and 6 poorly differentiated). The results of bisulfite sequencing using DNA extracted from cultivated lung cancer cells (Figure 4B) and in vivo adenocarcinoma cells (Figure $4 C$ ) revealed that methylation was hardly found in the NAB-2 promoter or in the EGR-1 or VEGF-A promoters. However, NAB-2 expression increased through the DNA methyltransferase inhibitor (5-aza-2'deoxycytosine) and/or histone deacetylase inhibitor (trichostatin $A$ ) treatment in three of seven lung cancer cell lines (TKB6, TKB14, and H358; Figure 4D). These findings suggested that NAB-2, EGR-1, and VEGF-A promoters are not directly affected by epigenetic alterations and indicated a possibility that unknown mechanisms, such as epigenetic silencing of transactivator(s) for $N A B-2$ gene expression, contribute to NAB-2 down-regulation in lung cancer cells.

\section{Discussion}

Angiogenesis mediated by VEGF-A expression in tumor cells is closely associated with the growth and metastasis of tumors. ${ }^{5-9}$ Under the hypoxic environment that predominates in solid tumors, HIF- $1 \alpha$ is an important inducer of VEGF-A. ${ }^{16,20}$ However, VEGF-A is induced not only by hypoxia but also by cytokines, sex hormones, growth factors, chemokines, and various genetic abnormalities (i.e., mutant oncosuppressor genes such as TP53 and 
VHL or mutation-activated oncogenes such as RAS, SRC, EGFR, and ERBB-2/HER2). ${ }^{39,47-49}$ Furthermore, Sparmann et al reported that PI3K/Akt/NF- $\kappa$ B and Raf/extracellular signal-regulated kinase/activator protein (ERK)-1 plays important roles on RAS-induced interleukin-8-mediated tumor angiogenesis. ${ }^{50}$ These reports indicated a possibility of direct association between EGR-1 and VEGF-A expression, because EGR-1 is induced by various stimuli such as growth factors ${ }^{51,52}$ and mutation-activated K-RAS upregulates EGR-1 through the ERK signaling in airway epithelial cells and lung cancer cells as we previously reported. ${ }^{23}$ It has also been reported that EGR-1 and NAB-2 play pivotal roles in vascular biology, especially in VEGF-A-mediated angiogenesis. ${ }^{53,54}$ However, obtaining evidence that EGR-1 directly regulates VEGF-A expression has heretofore been intractable because EGR-1 is immediately and transiently induced by various kinds of signals, and because conventional expression vector systems that result in sustained EGR-1 expression/overexpression reduce cell growth. ${ }^{24,55}$ We therefore established EGR-1-inducible lung cancer cells to allow strict examination of the alterations caused by EGR-1 up-regulation, and we could successfully provide direct evidence that EGR-1 activates VEGF-A in lung cancer cells in a HIF- $1 \alpha$-independent manner.

Gille et $a^{56}$ reported the transactivating mechanism of VEGF-A gene, focusing on the GC-rich promoter sequences located at the proximal region from the transcription start site, and demonstrated that AP-2 is important for transforming growth factor- $\alpha$-induced transcriptional activation of VEGF-A gene. Their examined region corresponded to the site 2-2, which revealed weak binding affinity with EGR-1 in comparison with site 1 or site 2-4 in our study. Our data and this report suggest the importance of transcription factors binding to the GC-rich promoter sequences for VEGF-A gene expression.

In our study, adenocarcinoma cell lines carrying the EGFR mutation expressed readily detectable levels of EGR-1 and VEGF-A as well as those carrying the mutant $K-R A S$. Surgically resected adenocarcinomas carrying mutant $K-R A S$ or EGFR also revealed relatively higher expression scores of EGR-1 than those carrying wild-type $K-R A S$ and EGFR. However, the differences were not statistically significant. From these results, it was considered that even adenocarcinomas carrying wild-type K-RAS and EGFR were exposed to various stimuli activating EGR-1, such as growth factors and cytokines, and therefore showed elevated EGR-1 expression in in vivo environment.

There have been reports suggesting that HIF- $1 \alpha$ plays an important role in VEGF-A expression and tumor development, that the expression of HIF- $1 \alpha$ mRNA is associated with disease progression in nonsmall-cell lung carcinoma tissues, and that $\mathrm{HIF-1} \alpha$ is a promising biomarker and therapeutic target. ${ }^{57,58}$ However, a large proportion of human tumors exhibit VEGF-A expression in the absence of HIF- $1 \alpha .{ }^{39}$ Although the VEGF-A promoter contains a HIF- $1 \alpha$ binding site, ${ }^{58}$ our study demonstrated negligible HIF- $1 \alpha$ expression in lung cancer cells cultivated under ordinary conditions, and luciferase reporter assays revealed no significant association between the
HIF- $1 \alpha$ binding site and VEGF-A promoter activity. However, we also demonstrated here that HIF- $1 \alpha$ was induced in lung cancer cells cultivated under hypoxic conditions and that EGR-1 expression enhanced HIF- $1 \alpha-$ induced VEGF-A expression. Consistent with these findings, immunohistochemical analysis indicated that many adenocarcinomas expressing EGR-1 expressed VEGF-A and that EGR-1-expressing adenocarcinomas with diffuse and intense nuclear HIF- $1 \alpha$ staining also exhibited elevated VEGF-A expression. Furthermore, both EGR-1 and HIF- $1 \alpha$ expression scores were correlated with VEGF-A expression scores. These findings suggest that EGR-1 plays a more significant role in VEGF-A expression in lung cancer cells than previously thought. ${ }^{24}$

Both NAB-2 and NAB-1 are crucial for controlling EGR1-mediated activation of transcription. NAB-1 is constitutively expressed in most cells ${ }^{25,26,28}$; likewise in the present study, NAB-1 expression was ubiquitous in cultivated lung cancer cells and in lung adenocarcinoma cells from pathological tissue sections (data not shown). Using EGR-1-inducible lung cancer cells, qRT-PCR analyses demonstrated that EGR-1 rapidly induced NAB-2 in cultivated lung cancer cells, as reported. ${ }^{29}$ And semiquantitative immunohistochemical analysis revealed that the expression scores of NAB-2 in lung adenocarcinoma cells were weakly correlated with those of EGR-1. However, immunohistochemical staining of surgically resected lung adenocarcinoma tissues revealed that NAB-2 expression was lower in moderately and poorly differentiated adenocarcinomas than in well-differentiated ones, whereas EGR-1 was more highly expressed in less differentiated tumors. These results indicated a disruption of the NAB-2-associated feedback loop against EGR-1 in in vivo lung cancers. We hypothesized that deficient NAB-2 expression might be caused by epigenetic silencing in association with cancer progression because the NAB-2 promoter contains $\mathrm{CpG}$ islands. However, no aberrant $N A B-2$ promoter methylation was identified in lung adenocarcinoma cells or in cultivated lung cancer cells. Furthermore, hypermethylation of $\mathrm{CpG}$ islands was not identified in the VEGF-A or EGR-1 promoters from cultivated and surgically resected lung cancer cells. These results suggest that regulation of VEGF-A expression via EGR-1 and NAB-2 is not affected by epigenetic events but is controlled by unknown mechanisms that disrupt the NAB-2/EGR-1 feedback loop in lung cancers in vivo. Because increase of NAB-2 expression through the DNA methyltransferase inhibitor and/or histone deacetylase inhibitor treatment was found in lung cancer cell lines examined, epigenetic silencing of transactivator(s) associated with NAB-2 gene expression might contribute to NAB-2 down-regulation in lung cancer cells.

In summary, we have demonstrated that EGR-1 upregulates the expression of VEGF-A in lung cancer cells by binding at specific sites in the VEGF-A promoter and also enhances HIF- $1 \alpha$-induced VEGF-A expression. Because VEGF-A expression in lung cancer cells is regulated by not only HIF- $1 \alpha$ but also by the EGR-1/NAB-2 feedback system, EGR-1 and NAB-2 may be useful as novel pharmaceutical targets in lung cancers. Further 
investigation is necessary to define the mechanisms leading to the decrease in NAB-2 expression in association with lung cancer progression.

\section{References}

1. Ferrara N, Davis-Smith $\mathrm{T}$ : The biology of vascular endothelial growth factor. Endocr Rev 1997, 18:4-5

2. Neufeld G, Cohen T, Gengrinovitch S, Poltorak Z: Vascular endothelial growth factor (VEGF) and its receptors. FASEB J 1999, 13:9-22

3. Gale NW, Yancopoulos GD: Growth factors acting via endothelial cell-specific receptor tyrosine kinases: VEGFs, angiopoietins, and ephrins in vascular development. Genes Dev 1999, 13:1055-1066

4. Ferrara N, Gerber HP, LeCouter J: The biology of VEGF and its receptors. Nat Med 2003, 9:669-676

5. Fontanini G, Vignati S, Boldrini L, Chine S, Silvestri V, Lucchi M, Mussi A, Angeletti CA, Bevilacqua G: Vascular endothelial growth factor is associated with neovascularization and influences progression of non-small cell lung carcinoma. Clin Cancer Res 1997, 3:861-865

6. Shibusa T, Shijubo N, Abe S: Tumor angiogenesis and vascular endothelial growth factor expressionin stage I lung adenocarcinoma. Clin Cancer Res 1998, 4:1483-1487

7. O'Byrne KJ, Koukourakis MI, Giatromanolaki A, Cox G, Turley H, Steward WP, Gatter K, Harris AL: Vascular endothelial growth factor, platelet-derived endothelial cell growth factor and angiogenesis in non-small-cell lung cancer. Br J Cancer 2000, 82:1427-1432

8. Han H, Silverman JF, Santucci TS, Macherey RS, d'Amato TA, Tung MY, Weyant RJ, Landreneau RJ: Vascular endothelial growth factor expression in stage I non-small cell lung cancer correlates with neoangiogenesis and a poor prognosis. Ann Surg Oncol 2001, 8:72-79

9. Decaussin M, Sartelet H, Robert C, Moro D, Claraz C, Brambilla C, Brambilla E: Expression of vascular endothelial growth factor (VEGF) and its two receptors (VEGF-R1-Flt1 and VEGF-R2-FIk1/KDR) in nonsmall cell lung carcinomas (NSCLCs): correlation with angiogenesis and survival. J Pathol 1999, 188:369-377

10. Yano S, Shinohara $H$, Herbst RS, Kuniyasu H, Bucana CD, Ellis LM, Fidler IJ: Production of experimental malignant pleural effusions is dependent on invasion of the pleura and expression of vascular endothelial growth factor/vascular permeability factor by human lung cancer cells. Am J Pathol 2000, 157:1893-1903

11. Ishii H, Yazawa T, Sato H, Suzuki T, Ikeda M, Hayashi $Y$, Takanashi $Y$, Kitamura $\mathrm{H}$ : Enhancement of pleural dissemination and lymph node metastasis of intrathoracic lung cancer cells by vascular endothelial growth factors (VEGFs). Lung Cancer 2004, 45:325-337

12. Wang GL, Jiang BH, Rue EA, Semenza GL: Hypoxia-inducible factor 1 is a basic helix-loop-helix-PAS heterodimer regulated by cellular $\mathrm{O}_{2}$ tenstion. Proc Natl Acad Sci USA 1995, 92:5510-5514

13. Bruick RK, McKnight SL: A conserved family of prolyl-4-hydroxylases that modify HIF. Science 2001, 294:1337-1340

14. Lando D, Peet DJ, Gorman JJ, Whelan DA, Whitelaw ML, Bruick RK $\mathrm{FIH}-1$ is an asparaginyl hydroxylase enzyme that regulates the transcriptional activity of hypoxia-inducible factor. Genes Dev 2002, 16:1466-1471

15. Sims KB: Von Hippel-Lindau disease: gene to bedside. Curr Opin Neurol 2001, 14:695-703

16. Rini BI, Rathmell WK: Biological aspects and binding strategies of vascular endothelial growth factor in renal cell carcinoma. Clin Cancer Res 2007, 13 (2 Suppl):741-764

17. Sekido Y, Bader S, Latif F, Gnarra JR, Gazdar AF, Linehan WM, Zbar B, Lerman MI, Minna JD: Molecular analysis of the von Hippel-Lindau disease tumor suppressor gene in human lung cancer cell lines. Oncogene 1994, 9:1559-1604

18. Miyakis S, Liloglou T, Kearney S, Xinarianos G, Spandidos DA, Field $\mathrm{JK}$ : Absence of mutations in the $\mathrm{VHL}$ gene but frequent loss of heterozygosity at 3p25-26 in non-small cell lung carcinomas. Lung Cancer 2003, 39:273-277

19. Liu Z, Zhao J, Chen XF, Li W, Liu R, Lei Z, Liu X, Peng X, Xu K, Chen J, Liu $H$, Zhou QH, Zhang HT: CpG island methylator phenotype involving tumor suppressor genes located on chromosome $3 p$ in non-small cell lung cancer. Lung Cancer 2008, 62:15-22

20. Mizukami Y, Li J, Zhang X, Zimmer MA, lliopoulos O, Chung DC: Hypoxia-inducible factor-1-independent regulation of vascular endo- thelial growth factor by hypoxia in colon cancer. Cancer Res 2004, 64:1765-1772

21. Mizukami Y, Fujiki K, Duerr EM, Gala M, Jo WS, Zhang X, Chung DC Hypoxic regulation of vascular endothelial growth factor through the induction of phosphatidylinositol 3-kinase/Rho/ROCK and c-Myc. J Biol Chem 2006, 281:13957-13963

22. Zhang X, Gaspard JP, Chung DC: Regulation of vascular endothelia growth factor by the Wnt and K-ras pathways in colonic neoplasia. Cancer Res 2001, 61:6050-6054

23. Sato H, Yazawa T, Suzuki T, Shimoyamada H, Okudela K, Ikeda M, Hamada K, Yamada-Okabe H, Yao M, Kubota Y, Takahashi T, Kamma $\mathrm{H}$, Kitamura $\mathrm{H}$ : Growth regulation via insulin-like growth factor binding protein-4 and -2 in association with mutant K-ras in lung epithelia. Am J Pathol 2006, 169:1550-1566

24. Gashler A, Sukhatme VP: Early growth response protein 1 (Egr1) prototype of a zinc-finger family of transcription factors. Prog Nucleic Acid Res Mol Biol 1995, 50:191-224

25. Russo M, Sevetson B, Milbrandt J: Identification of NAB1, a repressor of NGFI-A and Krox20 mediaated transcription. Proc Natl Acad Sci USA 1995, 92:6873-6877

26. Swirnoff AH, Apel ED, Svaren J, Sevetson BR, Zimonjic DB, Popescu NC, Milbrandt J: NAB1, a corepressor of NGFI-A (Egr-1), contains an active transcriptional repression domain. Mold Cell Biol 1998, 18:512-524

27. Svaren J, Sevetson B, Apel E, Zimonjic D, Popescu N, Milbrandt J: NAB2, a corepressor of NGFI-A (Egr-1), and Krox20, is induced by proliferative, and differentiative stimuli. Mold Cell Biol 1996, 16: 3545-3553

28. Thiel G, Kaufmann K, Magin A, Lietz M, Bach K, Cramer M: The human transcriptional repressor protein NAB1: expression and biological activity. Biochim Biophys Acta 2000, 1493:289-301

29. Kumbrink J, Gerlinger M, Johnson JP: Egr-1 induces the expression of its corepressor Nab2 by activation of the Nab2 promoter thereby establishing a negative feedback loop. J Biol Chem 2005, 280:42785-42793

30. Colby TV, Noguchi M, Henschke C, Vazquez MF, Geisinger K, Yokose T, Ohori P, Rami-Porta R, Franks T, Shimosato Y, Matsuno Y, Khoor A, Westra WH, Jambhekar NA, Petersen I, Takahashi T, Kawai T, Meyerson M, Hanash SM, Jen J: Adenocarcinoma. World Health Organization Classification of Tumours. Pathology and Genetics of Tumours of the Lung, Pleura, Thymus, and Heart. Edited by Travis WD, Brambilla E, Muller-Hermelink HK, Harris CC. Lyon, IARC Press, 2004, pp 35-44

31. Mitsudomi T, Yatabe $Y$ : Epidermal growth factor receptor in relation to tumor development: eGFR gene and cancer. FEBS J 2010, 277:301-308

32. Kosaka T, Yatabe $Y$, Endoh H, Kuwano H, Takahashi T, Mitsudomi T: Mutations of the epidermal growth factor receptor gene in lung cancer: biological and clinical implications. Cancer Res 2004, 64:9819-8923

33. Maegawa M, Arao T, Yokote H, Matsumoto K, Kudo K, Tanaka K, Kaneda H, Fujita Y, Ito F, Nishio K: EGFR mutation up-regulates EGR1 expression through the ERK pathway. Anticancer Res 2009, 29:1111-1117

34. Hirata A, Ogawa S, Kometani T, Kuwano T, Naito S, Kuwano M, Ono M: ZD1839 (Iressa) induces antiangiogenic effects through inhibition of epidermal growth factor receptor tyrosine kinase. Cancer Res 2002, 62:2554-2560

35. Okudela K, Yazawa T, Woo T, Sakaeda M, Ishii J, Mitsui H, Shimoyamada H, Sato H, Tajiri M, Ogawa N, Masuda M, Takahashi T, Sugimura $H$, Kitamura $H$ : Down-regulation of DUSP6 expression in lung cancer. Am J Pathol 2009, 175:867-881

36. Yazawa T, Sato H, Shimoyamada H, Okudela K, Woo T, Tajiri M, Ogura T, Ogawa N, Suzuki T, Mitsui H, Ishii J, Miyata C, Sakaeda M, Goto K, Kashiwagi K, Masuda M, Takahashi T, Kitamura H: Neuroendocrine cancer-specific up-regulating mechanism of insulin-like growth factor binding protein-2 in small cell lung cancer. Am J Pathol 2009, 175:976-987

37. Sato $H$, Hagiwara $H$, Senba $H$, Fukumoto $K$, Nagashima $Y$, Yamasaki $H$, Ueno K, Yano T: The inhibitory effect of connexin 32 gene on metastasis in renal cell carcinoma. Mol Carcinogenesis 2008, 47:403-409

38. Knight C, Slade JP, Carter D: The nuclear $75 \mathrm{kDa}$ form of early growth response protein-1/nerve growth factor-induced $A$ protein is primary restricted to $\mathrm{LH}$ beta-subunit-expressing cells in rat anterior pituitary. Eur J Endocrinol 2000, 143:817-821 
39. Jubb AM, Pham TQ, Frantz GD, Peale FV, Wu TD, Koeppen HW, Hillan KJ: Expression of vascular endothelial growth factor, hypoxia inducible factor $1 \alpha$, and carbonic anhydrase IX in human tumors. J Clin Pathol 2004, 57:504-512

40. Kim SJ, Rabbani ZN, Dewhirst MW, Vujaskovic Z, Vollmer RT, Schreiber EG, Oosterwijk E, Kelley MJ: Expression of HIF-1alpha. CA IX, VEGF, and MMP-9 in surgically resected non-small cell lung cancer Lung Cancer 2005, 49:325-335

41. Qu Z, Wolfraim LA, Svaren J, Ehrengruber MU, Davidson N, Milbrandt $\mathrm{J}$ : The transcriptional corepressor NAB2 inhibits NGF-induced differentiation of PC 12 cells. J Cell Biol 1998, 142:1075-1082

42. Ward R, Hawkins N, O'Grady R: Restriction endonuclease-mediated selective polymerase chain reaction. A novel assay for the detection of K-RAS mutations in clinical samples Am J Pathol 1998, 153:373-379

43. Okudela K, Woo T, Mitsui H, Yazawa T, Shimoyamada H, Tajiri M, Ogawa N, Masuda M, Kitamura H: Morphometric profiling of lung cancers - its association with clinicopathologic, biologic, and molecular genetic features. Am J Surg Pathol 2010, 34:243-255

44. Lynch TJ, Bell DW, Sordella R, Gurubhagavatula S, Okimoto RA, Brannigan BW, Harris PL, Haserlat SM, Supko JG, Haluska FG, Louis DN, Chrisiani DC, Settleman J, Haber DA: Activating mutations in the epidermal growth factor receptor underlying responsiveness of non-small-cell lung cancer to gefitinib. N Engl J Med 2004, 150:2129-2139

45. Sun L, Sakurai S, Sano T, Hironaka M, Kawashima O, Nakajima T: High-grade neuroendocrine carcinoma of the lung: comparative clinicopathological study of large cell neuroendocrine carcinoma and small cell lung carcinoma. Pathol Int 2009, 59:522-529

46. Forsythe JA, Jiang BH, lyer NV, Agani F, Leung SW, Koos R, Semenza GL: Activation of vascular endothelial growth factor gene transcription by hypoxia-inducible factor 1. Mol Cell Biol 1996, 16:4604-4613

47. Kerbel R: Folkman J: clinical translation of angiogenesis inhibitors. Nat Rev Cancer 2002, 2:727-739

48. Kerbel RS: Molecular origins of cancer. Tumor angiogenesis N Engl J Med 2008, 358:2039-2049
49. Mizukami Y, Kohgo Y, Chung DC: Hypoxia inducible factor-1-independent pathways in tumor angiogenesis. Clin Cancer Res 2007, 13:5670-5674

50. Sparmann A, Bar-Sagi D: Ras-induced interleukin-8 expression plays a critical role in tumor growth and angiogenesis. Cancer Cell 2004, 6:447-458

51. Schwachtgen JL, Campbell CJ, Braddock M: Full promoter sequence of human early growth factor-1 (Egr-1): demonstration of a fifth functional serum response element. DNA Seq 2000, 10:429-432

52. Gaggioli C, Deckert M, Robert G, Abbe P, Batoz M, Ehrengruber MU, Ortonne JP, Ballotti R, Tartare-Deckert S: HGF induces fibronectin matrix synthesis in melanoma cells through MAP kinase-dependent signaling pathway and induction of Egr-1. Oncogene 2005, 24:1423-1433

53. Fahmy RG, Dass CR, Sun LQ, Chesterman CN, Khachigian LM: Transcription factor Egr-1 supports FGF-dependent angiogenesis during neovascularization and tumor growth. Nat Med 2003, 9:1026-1032

54. Lucerna M, Mechtcheriakova D, Kadl A, Schabbauer G, Schafer R, Gruber F, Koshelnick Y, Muller HD, Issbrucker K, Clauss M, Binder BR, Hofer E: NAB2, a corepressor of EGR-1, inhibits vascular endothelial growth factor-mediated gene induction and angiogenic responses of endothelial cells. J Biol Chem 2003, 278:11433-11440

55. Huang RP, Liu C, Fan Y, Mercola D, Adamson ED: Egr-1 negatively regulates human tumor cell growth via the DNA-binding domain. Cancer Res 1995, 55:5054-5062

56. Gille J, Swerlick RA, Caughman SW: Transforming growth factor- $\alpha$ induced transcriptional activation of the vascular permeability factor (VPF/NEGF) gene requires AP-2-dependent DNA binding and transactivation. EMBO J 1997, 16:750-759

57. Enatsu S, Iwasaki A, Shirakusa T, Hamasaki M, Nabeshima K, Iwasaki $\mathrm{H}$, Kuroki M, Kuroki M: Expression of hypoxia-inducible factor-1 alpha and its prognostic significance in small-sized adenocarcinomas of the lung. Eur J Cardiothorac Surg 2006, 29:891-895

58. Yohena Y, Yoshino I, Takenaka T, Kameyama T, Ohba T, Kuniyoshi Y Maehara Y: Upregulation of hypoxia-inducible factor- $1 \alpha$ mRNA and its clinical significance in non-small cell lung cancer. J Thorac Oncol 2009, 4:284-290 